(C) 2018. This manuscript version is made available under the CCBY-NC-ND 4.o license http://creativecommons.org/licenses/by-nc-nd/4.0/ 


\section{Accepted Manuscript}

Using mobility information to perform a feasibility study and the evaluation of spatio-temporal energy demanded by an electric taxi fleet

Jesús Fraile-Ardanuy, Sandra Castano-Solis, Roberto Álvaro-Hermana, Julia Merino, Ángela Castillo

PII: S0196-8904(17)31122-6

DOI: https://doi.org/10.1016/j.enconman.2017.11.070

Reference: ECM 9810

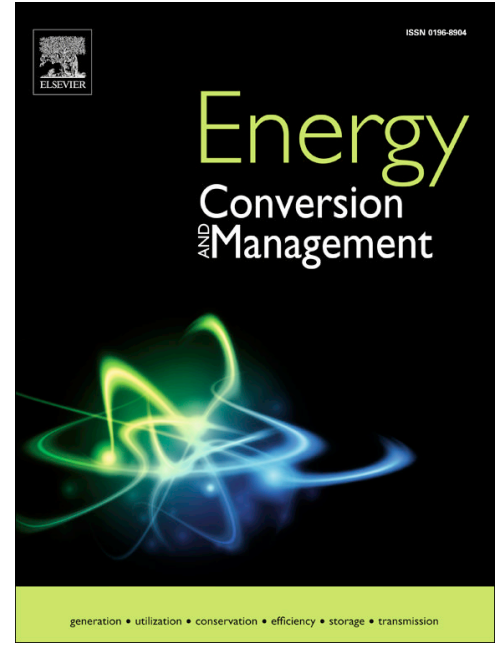

To appear in:

Energy Conversion and Management

Received Date:

13 May 2017

Revised Date:

19 October 2017

Accepted Date:

23 November 2017

Please cite this article as: J. Fraile-Ardanuy, S. Castano-Solis, R. Álvaro-Hermana, J. Merino, A. Castillo, Using mobility information to perform a feasibility study and the evaluation of spatio-temporal energy demanded by an electric taxi fleet, Energy Conversion and Management (2017), doi: https://doi.org/10.1016/j.enconman. 2017.11.070

This is a PDF file of an unedited manuscript that has been accepted for publication. As a service to our customers we are providing this early version of the manuscript. The manuscript will undergo copyediting, typesetting, and review of the resulting proof before it is published in its final form. Please note that during the production process errors may be discovered which could affect the content, and all legal disclaimers that apply to the journal pertain. 


\title{
Using mobility information to perform a feasibility study and the evaluation of spatio-temporal energy demanded by an electric taxi fleet
}

\author{
Jesús Fraile-Ardanuy $^{\mathrm{a}^{*},}$ Sandra Castano-Solis ${ }^{\mathrm{b}}$, Roberto Álvaro-Hermana ${ }^{\mathrm{c}}$, Julia Merino ${ }^{\mathrm{d}}$, \\ Ángela Castillo ${ }^{\mathrm{a}}$ \\ ${ }^{a}$ Information Processing and Telecommunications Center. ETSI Telecomunicación-UPM. Avda. Complutense 30, 28040 Madrid, Spain \\ ${ }^{b}$ Departamento de Ingeniería Eléctrica, Electrónica, Automática y Física Aplicada, Universidad Politécnica de Madrid. Ronda de \\ Valencia 3, 28012, Madrid, Spain \\ ${ }^{c}$ ORKESTRA-Fundación Deusto, Universidad de Deusto, Av. de las Universidades, 24, 48007, Bilbao \\ ${ }^{d}$ Tecnalia R\&D. Parque Tecnológico de Bizkaia.C/Geldo, Edificio 700. 48160 Derio-Bizkaia, Spain
}

* Corresponding author: jesus.fraile.ardanuy@upm.es

\begin{abstract}
Half of the global population already lives in urban areas, facing to the problem of air pollution mainly caused by the transportation system. The recently worsening of urban air quality has a direct impact on the human health. Replacing today's internal combustion engine vehicles with electric ones in public fleets could provide a deep impact on the air quality in the cities. In this paper, real mobility information is used as decision support for the taxi fleet manager to promote the adoption of electric taxi cabs in the city of San Francisco, USA. Firstly, mobility characteristics and energy requirements of a single taxi are analyzed. Then, the results are generalized to all vehicles from the taxi fleet. An electrificability rate of the taxi fleet is generated, providing information about the number of current trips that could be performed by electric taxis without modifying the current driver mobility patterns. The analysis results reveal that $75.2 \%$ of the current taxis could be replaced by electric vehicles, considering a current standard battery capacity (24-30 kWh). This value can increase significantly (to 100\%), taking into account the evolution of the price and capacity of the batteries installed in the last models of electric vehicles that are coming to the market. The economic analysis shows that the purchasing costs of an electric taxi are bigger than conventional one. However, fuel, maintenance and repair costs are much lower. Using the expected energy consumption information evaluated in this study, the total spatio-temporal demand of electric energy required to recharge the electric fleet is also calculated, allowing identifying optimal location of charging infrastructure based on realistic routing patterns. This information could also be used by the distribution system operator to identify possible reinforcement actions in the electric grid in order to promote introducing electric vehicles.
\end{abstract}

Keywords- Big data, Mobility pattern, GPS Data, Electric vehicle, Charging Stations, Spatial-temporal electricity demand.

\section{Introduction}

More than a half of the world population is living in crowed cities, attracted by better opportunities [1], but this high concentration of human beings has led to huge unsolved problems like unplanned housing, water and energy availability, urban waste, access to basic services, stress on the public infrastructure and water and air quality [2].

Air pollution is responsible for the significant growth in chronic health problems on the urban population like respiratory and heart diseases [3]. Most of these problems are directly related to transportation systems [4]. Conventional internal combustion engine (ICE) vehicles are responsible for the emission of $73 \%$ of the total urban air pollutants [5]. Introducing electric vehicles (EVs) in big cities can be a key factor to reduce these pollutant emissions [6]. Depending on the electricity generation mix of a specific region, the GHG emissions can even increase if a widespread adoption of EV are promoted when a primary source of electric power is based on fossil fuel generation [7].

Governments are promoting the replacement of ICE vehicles with EVs to reduce the cities' greenhouse gas (GHG) emissions and pollutants. Different initiatives have been developed in Europe [8-9], USA [10] and China [11] among others. This transition can be led by public urban fleets, such as buses, postal delivery vehicles or taxis, because these type of vehicles travel short and repetitive routes and many of these toxic 
pollutants are concentrated in the same areas of the city that have a high density of urban fleet movements [12].

EVs could provide positive effects for the whole urban population: improvement of the air quality in urban areas, reduced noise pollution, and a significant reduction of the urban temperature due to the reduction of heat emission [13]. This transition not only benefits citizens, but can also benefits fleet operators: EVs have a higher initial cost of purchasing, but they have a lower total cost of ownership. The operational running costs are significantly lower than for ICE vehicles, due to reduced fuel spending, lower maintenance and other financial benefits (i.e. tax reduction and other government incentives) [14]. An EV fleet also helps to strength the company's brand image, promoting a social environmental responsibility. The replacement of ICE fleet vehicles with EVs requires a detailed study by the fleet manager, taking into account the fleet's whole life cost.

There are two main limiting factors for the adoption of EVs: the purchase price and the limited range. The first restriction can be solved through taxation and other financial benefits promoted by public institutions. The second restriction can be solved through an analysis of the real fleet mobility requirements, providing a deep understanding of the operational patterns of the real vehicles.

From this information it is possible to evaluate the potential of EVs to meet the fleet mobility requirements, helping the fleet operator to make a seamless transition to a zero-emission vehicle fleet. With the current increasing volume of mobility data available, this potential can be performed through a data-driven analysis.

GPS traces have been previously used in transportation research to validate travel surveys [15] and analyze traffic intensity and movement speed in cities [16].

In [17] GPS traces from ICE light vehicles provided by a private insurance company have been used to evaluate the potential of EVs to meet the current mobility demand in two different Italian cities. In this analysis, the potential electric energy demand is calculated based on fixed consumption values obtained from the car manufacturers or by the US Environmental Protection Agency (EPA) tests, depending of the type of EV considered.

In other works, GPS taxi traces have been applied to evaluate the waiting time of empty taxis [18] for nearest pick-up areas recommendation [19-20] and also to discover spatio-temporal cluster patterns [21]. Specific GPS taxi traces has been used to understand the operational and charging behaviors of electric taxis, identifying the main differences with conventional ICE taxi vehicles [22].

In this paper, real mobility taxi GPS traces from San Francisco (USA) are analyzed to evaluate the possible adoption of EVs in a real taxi fleet. In Section II, the proposed method is described in detail. In section III a feasibility study is performed, where firstly, a single EV taxi is analyzed and then, this analysis is extended to the rest of the vehicles that compose this taxi fleet. An electrificability rate of the taxi fleet is generated, providing information about the number of current trips that could be performed by EVs without modifying the current taxi mobility patterns. Using the expected energy consumption information, the total spatiotemporal demand of electric energy required to recharge the EV fleet is also evaluated. This information can be used to identify optimal location of the charging infrastructure and additionally, this data could be used by the distribution system operator (DSO) to identify possible reinforcement actions in the electric grid. Finally, conclusions and discussions are provided in Section IV.

\section{Methods}

For this study, the mobility data description is initially presented. Then, several calculations are performed to study the real mobility of each vehicle (evaluation of the traveled distance, speed, etc.). With this information, different charging event opportunities are evaluated, determining the stops with a time duration that exceed half an hour. It is assumed that during these periods, EV taxis will be charged from 5-80\% nominal capacity with a DC fast charger [23]. The location and the total duration of these stops are also registered.

The next step is to develop an EV consumption model to estimate the expected electric energy consumption. This model takes into account the driving distance, the speed, the taxi status and the terrain elevation. 


\subsection{GPS data description}

Taxi companies around the world have begun to install GPS tracking devices to analyse operational patterns of EV [18-20] and provide an efficient taxi dispatch to their customers [22-23].

The data utilized in this work consists of 8.6 million GPS traces from 466 ICE taxis collected over 30 days (May 17th to June 15th, 2011) in the city of San Francisco, USA. Each trace contains latitude and longitude coordinates, a binary variable indicating the taxi occupancy status ( 1 when the taxi is carrying a customer and 0 when it is empty) and finally, a timestamp in UNIX time (representing the number of seconds that have elapsed since January, $1^{\text {st }}, 1970$ ) [25]. The average timestep between two consecutive samples is around 90 seconds.

The GPS data was analysed before using it and some inconsistences were detected, removing the data corresponding to six vehicles from the original 466 data set.

\subsection{Mobility calculation}

The recorded GPS traces do not contain information about the terrain elevation, but this is one of the main factors influencing the vehicle consumption. Therefore, it is important to obtain this data and add it to the GPS traces for further consideration in the analysis. In this work, the altitude of the latitude-longitude data set has been extracted from US Geological Survey National Elevation Dataset [25].

With this additional information, the total distance between two consecutive GPS traces is evaluated, as it is described in Figure 1. Firstly, the distance between two consecutive coordinates over the earth's surface is calculated based on the basis of spherical earth and ignoring the ellipsoidal effects, which is accurate enough for this work, where two consecutive coordinates are only separated by tens of kilometers. There are several ways to calculate this distance: using a planar approximation, the Haversine formula or the spherical law of cosines. This last option was used in this work [26]. With this information, and the elevation of both coordinates, the real travelled distance and the elevation angle (also called, angle of the driving surface, $\alpha$, in the model) are finally evaluated.

Adding up these intermediate distances between consecutives coordinates, will allow to calculate the total distance travelled during a particular time period.

The average speed between two consecutive latitude-longitude coordinates is also evaluated, providing additional information about the taxi's speed.
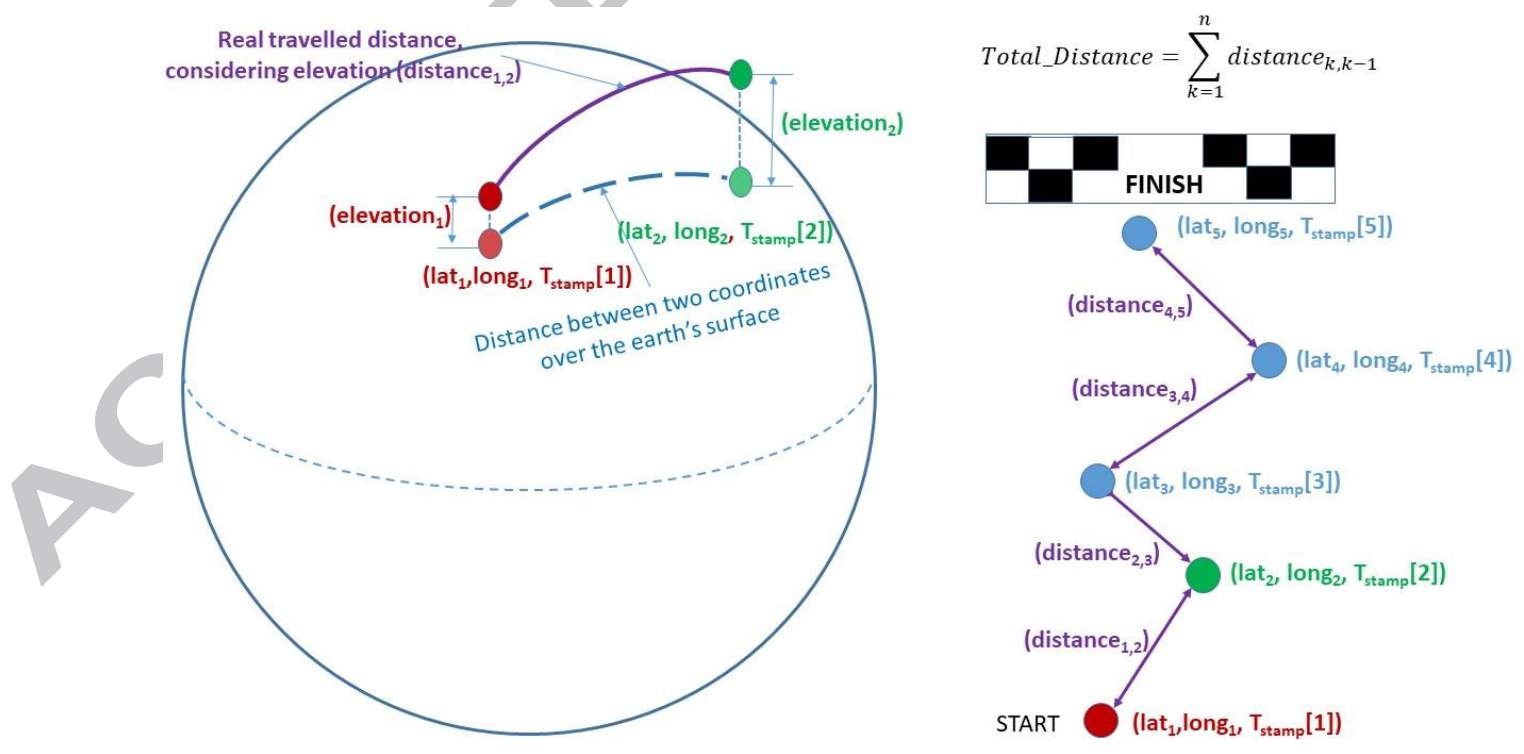

Fig 1. Calculation of the driving distance between two consecutive coordinates. 


\subsection{Understanding taxi mobility behavior and detecting the charging event possibility}

It is important to clearly understand the real taxi mobility behavior to perform the feasibility studies for EV deployment in a taxi fleet. For this study, it is assumed that the mobility behavior would not change when the taxi fleet operator replaces its conventional ICE vehicles with new EV ones. This assumption ignores the possible variation in the EV use due to its deployment.

Analyzing the current taxi mobility, it is observed that most vehicles are operating during all day. The reason is that taxi fleet operators always want to maximize their revenues, minimizing the resting time. In this case, taxi cabs belong to a single fleet operator and the drivers who work for it, operate in a double-shift scheme (vehicles are driven 12-16 hours per day).

Although most taxis are double-shifted, drivers must take breaks during their working periods. In this work, it has been considered that quick chargers are used to recharge their vehicles during this resting period.

A trip is defined as the set of consecutive GPS traces between two stops with a duration larger than a time threshold of 30 minutes, as shown in Figure 2. A single trip can contain several empty-occupied states (subtrips). For example, trip \#1 starts at $\mathrm{T}_{\text {stamp }}[1]$ when the taxi cab is initially for hire (denoted by the green dot). The taxi is moving, looking for a passenger until $\mathrm{T}_{\text {stamp }}[\mathrm{i}]$. In this moment, the driver picks up a customer (denoted by the red dot). The passenger is dropped off at the final destination, and the taxi cab keeps moving around until $\mathrm{T}_{\text {stamp }}[\mathrm{k}]$, when the vehicle stops. When the time interval between two consecutive time stamps, $\mathrm{T}_{\text {stamp }}[\mathrm{k}+1]-\mathrm{T}_{\text {stamp }}[\mathrm{k}]$, is larger than 30 minutes, a charging event possibility is detected.

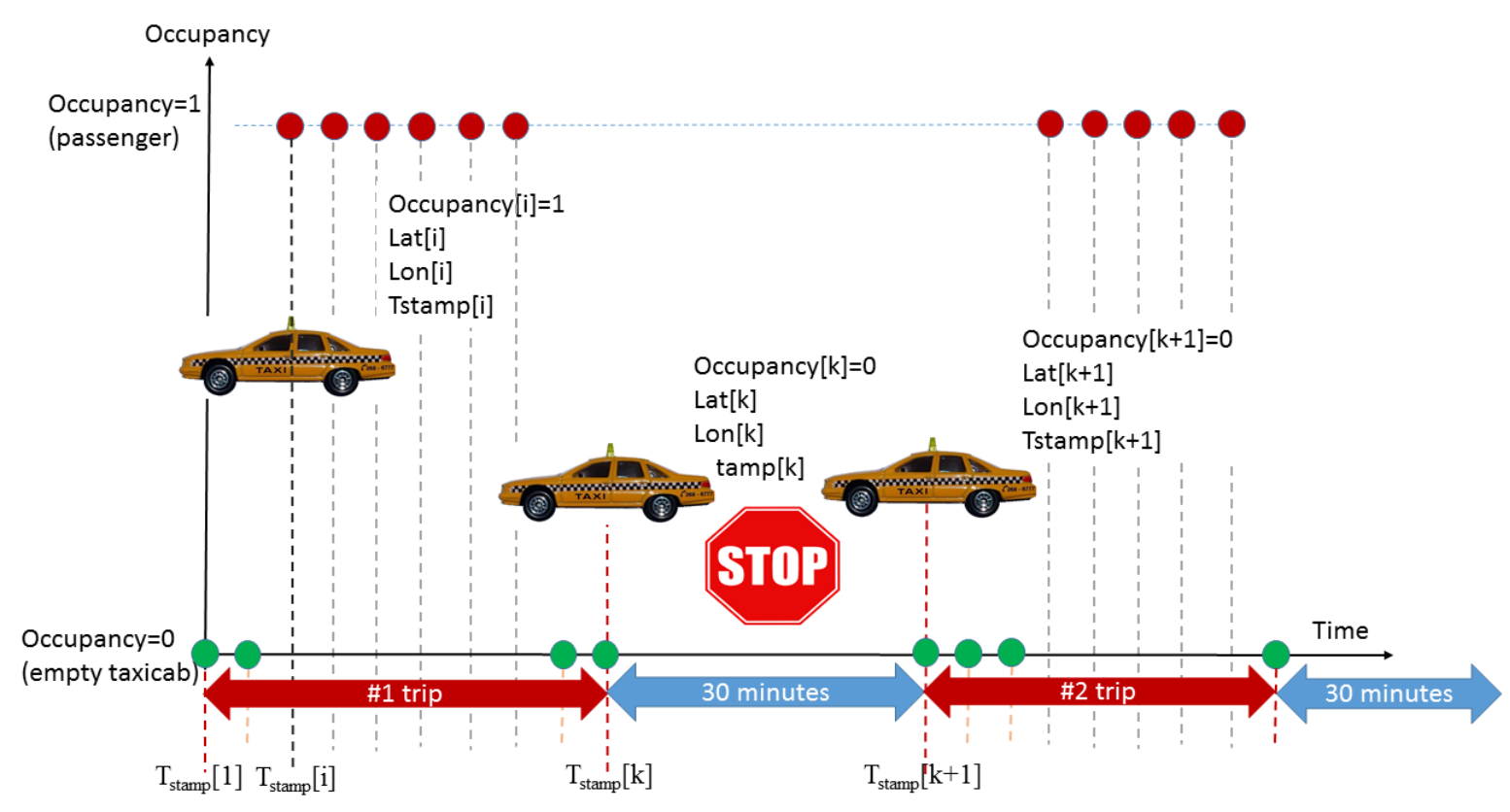

Fig 2. Trip definition.

From the GPS raw data, the downtime periods above 30 minutes are identified and their duration and location (latitude-longitude coordinates) are stored. The original dataset is then split into different consecutive trips, allowing the evaluation of the total distance per trip and the average vehicle speed for each trip, as it was shown in Figure 2.

One of the objectives of this work is to estimate the number of taxi trips which could potentially be done by EVs. It is initially assumed that all taxis are electric, with a nominal capacity of $24 \mathrm{kWh}$, and they are fully charged at the beginning of the first day.

For each trip, an EV consumption model, described in the following subsection, estimates the energy consumption and this value is subtracted to the nominal battery capacity, updating the battery State of Charge (SoC). After each trip update, if the battery SoC is above a threshold (10\% of the nominal capacity), the trip is identified as feasible to be done using an EV. 
Taxi vehicles typically drive around $200 \mathrm{~km}$ per shift [12], requiring fast charging to power this type of high-mileage, time-constrained vehicles. In this work it is assumed that all EV taxis under study are equipped for $50 \mathrm{~kW}$ DC fast charging capability, which can provide an $80 \%$ charge during these 30 minute stops.

\subsection{Electric vehicle consumption model}

The proposed EV consumption model is derived from the physical relationship between the forces acting on the electric vehicle and it is based on [27]. These forces are shown in Figure 3.

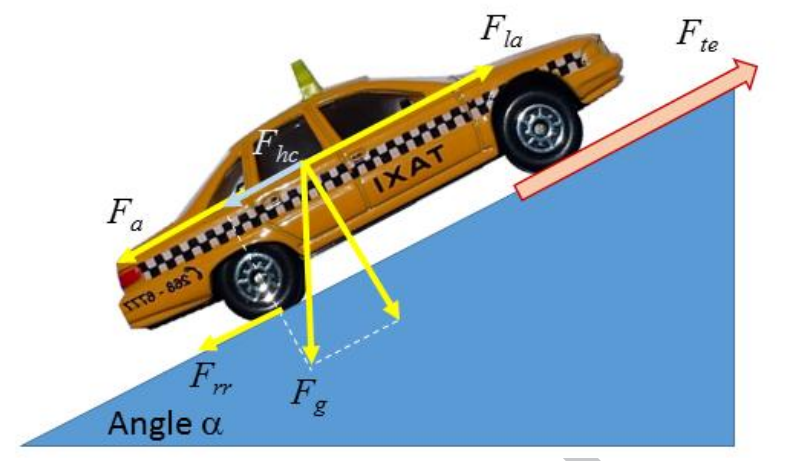

Fig 3. Dynamic longitudinal model

The forces acting on the vehicle are defined by (1)-(4):

$$
\begin{aligned}
& F_{\mathrm{rr}}=R\left(M_{c a r}+M_{d}\right) g \cos \alpha \\
& F_{\mathrm{a}}=\frac{1}{2} A C_{d} \rho v^{2} \\
& F_{\mathrm{hc}}=\left(M_{c a r}+M_{d}\right) g \sin \alpha \\
& F_{\mathrm{ia}}=1.05\left(M_{c a r}+M_{d}\right) a
\end{aligned}
$$

Where $F_{r r}$ represents the rolling resistance force, $F_{a}$ is the aerodynamic drag, $F_{h c}$ is de vehicle's weight component and finally, $F_{i a}$ represents the inertial force. The additional variables and parameters are the following: $R$ defined the tire rolling resistance coefficient, $M_{c a r}$ is the mass of the vehicle, $M_{d}$ is the mass of the people in the vehicle (only the driver when the taxi cab is empty and driver plus passengers when it is occupied), $g$ is the gravity acceleration $\left(9.81 \mathrm{~m} / \mathrm{s}^{2}\right), \alpha$ is the angle of the driving surface, $A$ is the front area of the vehicle, $C_{d}$ is the aerodynamic drag coefficient, $\rho$ is the air density of dry air at $20^{\circ} \mathrm{C}\left(1.2041 \mathrm{~kg} / \mathrm{m}^{3}\right), v$ represents the vehicle's speed and $a$ is the acceleration of the vehicle. These parameters define the vehicle dynamics [28-29] and they could be applied to electric vehicles too [30].

It is important to highlight that $M_{d}$ depends on the taxi status. If the taxi is not occupied, this parameter only model the driver's weight. If the taxi is occupied, this parameter considers the total weight of the driver, the passenger(s) and the luggage.

The tractive force that must be overcome by the electric motor is shown in (5):

$$
\mathrm{F}_{\mathrm{te}}=\mathrm{F}_{\mathrm{rr}}+\mathrm{F}_{\mathrm{a}}+\mathrm{F}_{\mathrm{hc}}+\mathrm{F}_{\mathrm{ia}}
$$

Finally, the mechanical tractive power is given by (6): 


$$
\mathrm{P}_{\mathrm{te}}=\mathrm{F}_{\mathrm{te}} v
$$

This mechanical power is applied directly to the wheels in normal forward driving (7):

$$
\mathrm{P}_{\mathrm{wh}}=\mathrm{P}_{\mathrm{te}}
$$

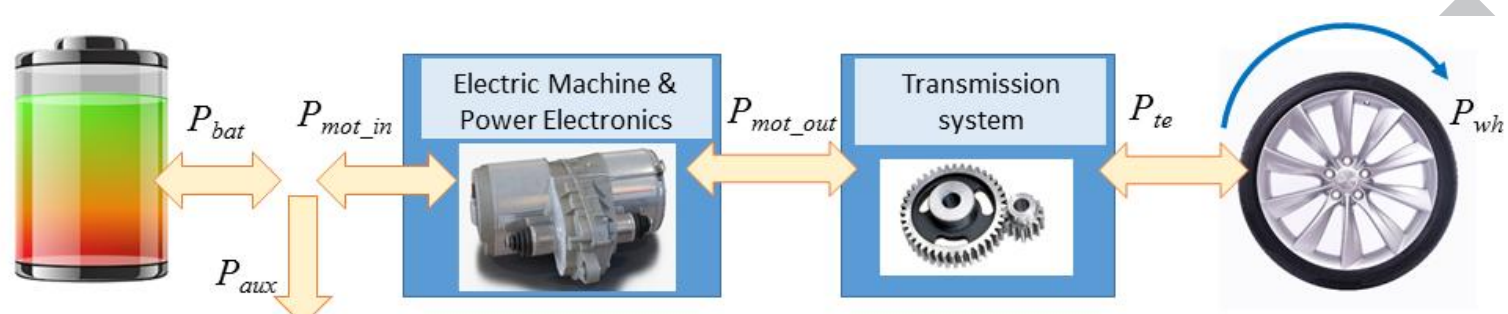

Auxiliary loads

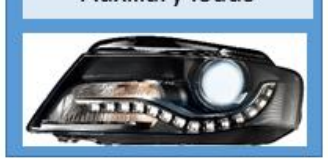

Fig 4. Energy flow in the EV with regenerative braking.

This tractive power is derived at each time step. To predict the total range of the EV taxi, it is necessary to evaluate the energy required to move the vehicle each time step, as it is shown in Figure 4. This energy is subtracted to the battery capacity until the battery is completely empty.

In normal forward driving, $P_{w h}>0$ and $P_{t e}>0$ during a time interval $\Delta t$. The energy is consumed to propel the EV, extracting energy from the battery $\left(P_{b a t} \Delta t>0\right)$.

$P_{t e}$ and $P_{b a t}$ are linked through the following equations (8)-(10), where $P_{\text {mot_out }}$ represents the mechanical power extracted from the electric motor, $\eta_{g e a r}$ is the transmission system efficiency, $P_{\text {mot }}$ in represents the electric power extracted from the battery to feed the electric motor and the power electronics, $\eta_{m o t}$ is the efficiency of the electrical motor and power electronics, and $P_{a u x}$ represents the variable auxiliary loads (lights, wipers, indicators, etc.)

$$
\begin{aligned}
& P_{\text {mot_out }}=\frac{P_{\text {te }}}{\eta_{\text {gear }}} \\
& P_{\text {mot_in }}=\frac{P_{\text {mot_out }}}{\eta_{\text {mot }}} \\
& P_{\text {bat }}=P_{m o t_{-} \text {in }}+P_{a u x}
\end{aligned}
$$

During breaking, EVs recover a fraction of the breaking energy, recharging the battery pack. The fraction of regeneration of breaking energy is defined as $0<R_{\text {gen_ratio }}<1$. In this case, the power applied through the wheels is negative $P_{w h}<0$ and the mechanical tractive power is also negative, $P_{t e}<0$. Notice that, this value will be weighted by the regeneration factor, flowing back from the wheels to the electric machine and from it to the battery (11)-(14).

$$
\begin{aligned}
& P_{t e}=R_{\text {gen_ratio }} P_{w h} \\
& P_{\text {mot_out }}=\eta_{\text {gear }} P_{t e}
\end{aligned}
$$




$$
\begin{aligned}
& P_{m o t_{-} \text {in }}=\eta_{m o t} P_{m o t_{-} \text {out }} \\
& P_{b a t}=P_{m o t_{-} \text {in }}+P_{a u x}
\end{aligned}
$$

Battery performance is modeled to simulate battery operation, extracting/injecting power in every simulation step, $\Delta t$, and estimating the State of Charge (SoC) [31-32]. Several different models are proposed in the literature to simulate the behavior of electric vehicles. Probably the most used models are based on an equivalent circuit composed by a controlled voltage source in series with an equivalent battery impedance [33]. Other models are focused on representing the behavior of an EV during charging and discharging processes [34]. However, in order to integrate the EV model in simulations involving thousands of different real trajectories, a more simplified model based on [35], suitable for real-time applications has been used in this work.

In normal forward driving, the battery is discharged. The energy extracted from it, $E_{b a t}$, depends on the total battery power demanded by the vehicle in each time step and the battery efficiency $\eta$ :

$$
E_{b a t}=\frac{P_{b a t} \cdot \Delta t}{\eta}
$$

During the braking, the energy is injected back to the battery, through the battery efficiency $\eta$.

$$
E_{b a t}=\eta \cdot P_{b a t} \cdot \Delta t
$$

The state of charge (SoC) estimation is given by:

$$
\operatorname{SoC}[k]=\operatorname{SoC}[k-1]+\frac{1}{C_{\text {nom }}} \sum_{j} i[j] . \Delta t
$$

The value of the main model parameters used in this model are presented in Table 1 [35-36].

\begin{tabular}{llll} 
& \multicolumn{3}{c}{ Table 1. EV Consumption model parameters } \\
\hline Description & \multicolumn{1}{c}{ Symbol } & Value & Unit \\
\hline Cross sectional área & $A$ & 2.27 & $\mathrm{~m}^{2}$ \\
Curb weight & $M_{c a r}$ & 1521 & $\mathrm{~kg}$ \\
Driver weight & $M_{d}$ & 75 & $\mathrm{~kg}$ \\
Drag coefficient & $C_{d}$ & 0.29 & \\
Coefficient of rolling resistance & $R$ & 0.012 & \\
Regeneration ratio & $R_{\text {gen_ratio }}$ & 0.25 normal mode / $0.35 \mathrm{ECO}$ mode \\
Nominal battery capacity & $C_{\text {nom }}$ & 24 & $\mathrm{kWh}$ \\
Low battery threshold & & 10 & $\%$ \\
Gear efficiency & $\eta_{\text {gear }}$ & 0.95 & $\%$ \\
Electric motor and power electronic eff. & $\eta_{\text {mot }}$ & 0.98 & $\%$ \\
Battery efficiency & $\eta$ & 0.98 & $\%$ \\
\hline
\end{tabular}




\subsection{Electric vehicle consumption model validation}

Most of the conventional taxis used in the taxi fleet have similar characteristics to Nissan Leaf (2015 version). This model of EV has also been used as taxi cab in several cities around the world [38-39] and has been considered in this work as representative vehicle for the electric taxi fleet.A complete description of all parameters from its dynamic longitudinal model is currently published by [36] and [37]. This 5-door hatchback EV is powered by an $80 \mathrm{~kW}$ synchronous motor with a nominal $24 \mathrm{kWh}$ lithium ion battery.

This 2015 version was tested under the standardized EPA Urban Dynamometer Driving Schedule, a laboratory test commonly called the LA4 test cycle, which represents city driving conditions. The speed profile of this drive cycle is presented in Figure 5. The maximum speed is $91.2 \mathrm{~km} / \mathrm{h}$ and the average speed is $31.507 \mathrm{~km} / \mathrm{h}$.

The range provided by the car manufacturer under US LA4 standardized city driving schedule is $160 \mathrm{~km}$, corresponding to $0.15 \mathrm{kWh} / \mathrm{km}$ [38]. The electric vehicle consumption model described in section 2.4 estimates a real range of $157.7 \mathrm{~km}$ for the same LA4 test cycle, which is a very good approximation.

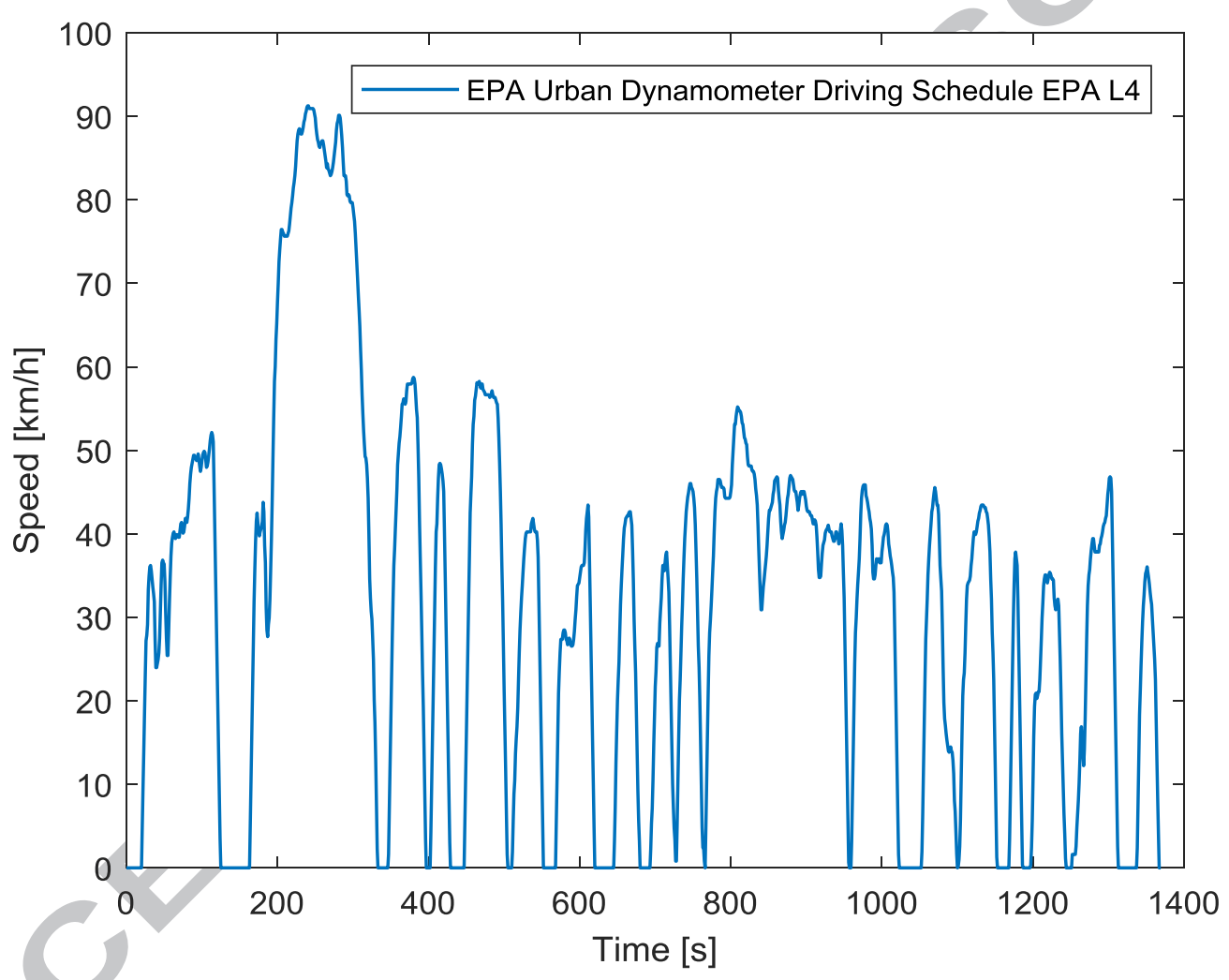

Fig 5. Speed profile of the USA LA4 drive cycle test.

\section{Feasibility analysis results}

In this section, the feasibility analysis to assess the suitability of EV taxis is presented. In the first part of this study, operational mobility and energy requirements of a single taxi are determined. The second part extends the analysis to all vehicles from the taxi fleet. 


\subsection{Single vehicle analysis}

The characteristics of real routing patterns such as stops (with a duration exceeding 30 minutes), and the traveling distance between two consecutive stops are evaluated to determine the taxi's requirements mobility. This mobility information is later used to calculate the spatio-temporal energy demanded and the number of trips that can be completed by the electric taxi. This defines the electrificability rate of this particular vehicle.

\subsubsection{Mobility information}

It is essential to clearly understand the specific operational mobility issues that taxi fleet managers have to face in the adoption of EVs as taxi vehicles. In this section, these issues are analyzed in detail for a single taxi cab. The taxi under study has been randomly chosen among all vehicles in the fleet. The number of registered days of this particular taxi is 24 (49 different trips). In that time, 48 stops with a duration above 30 minutes have been identified.

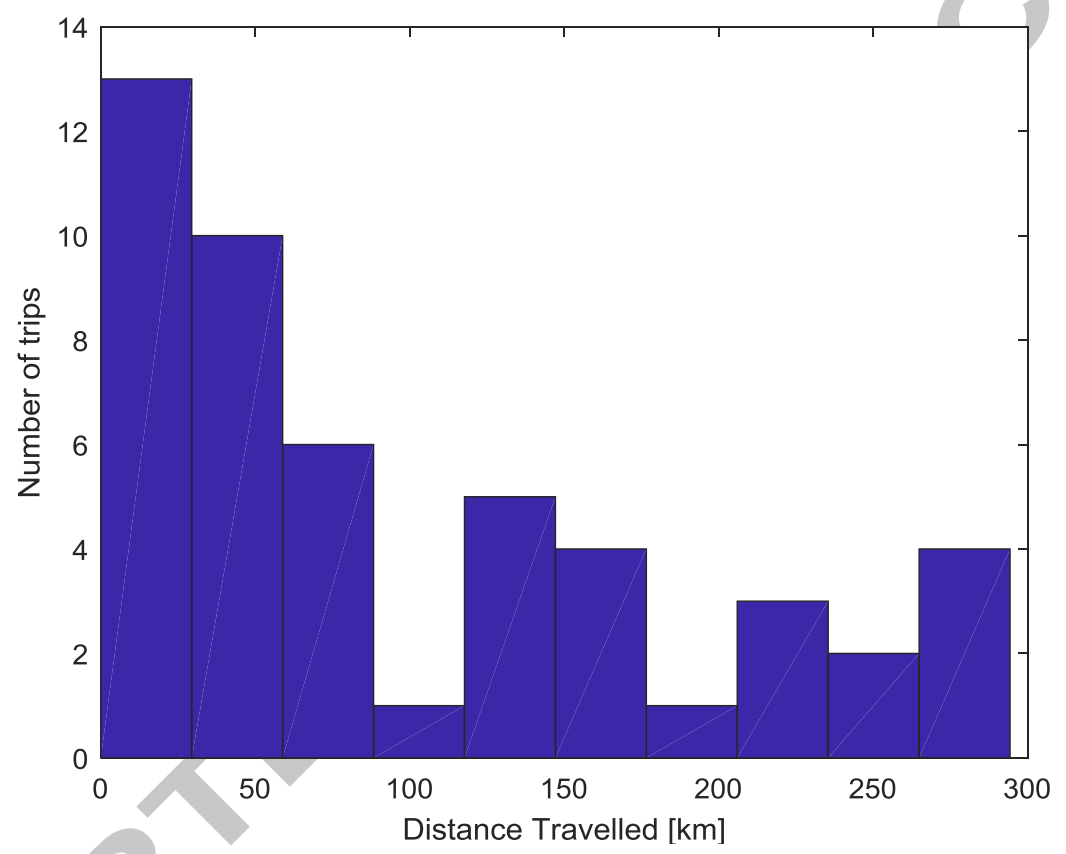

Fig 6. Histogram of distance travelled between two consecutive stops above 30 minutes for a single taxi cab

Figure 6 shows the distribution of the distance travelled between two consecutive stops. It is observed that most of the distances covered by this vehicle are below $150 \mathrm{~km}$ (36 trips, $73.47 \%$ of all recorded trips), but there are some long trips above $250-300 \mathrm{~km}$ ( 6 trips, $12.2 \%$ of all recorded trips).

To evaluate the best location for the charging stations deployment, it is important to know when and where taxi cabs are parked during their daily trips and how long are parked. Figure 7 shows a bubble plot containing the 48 stop locations above 30 minutes performed by this particular taxi during the period under study. The duration of each stop is proportional to the circle radius, as it is described in the legend. 


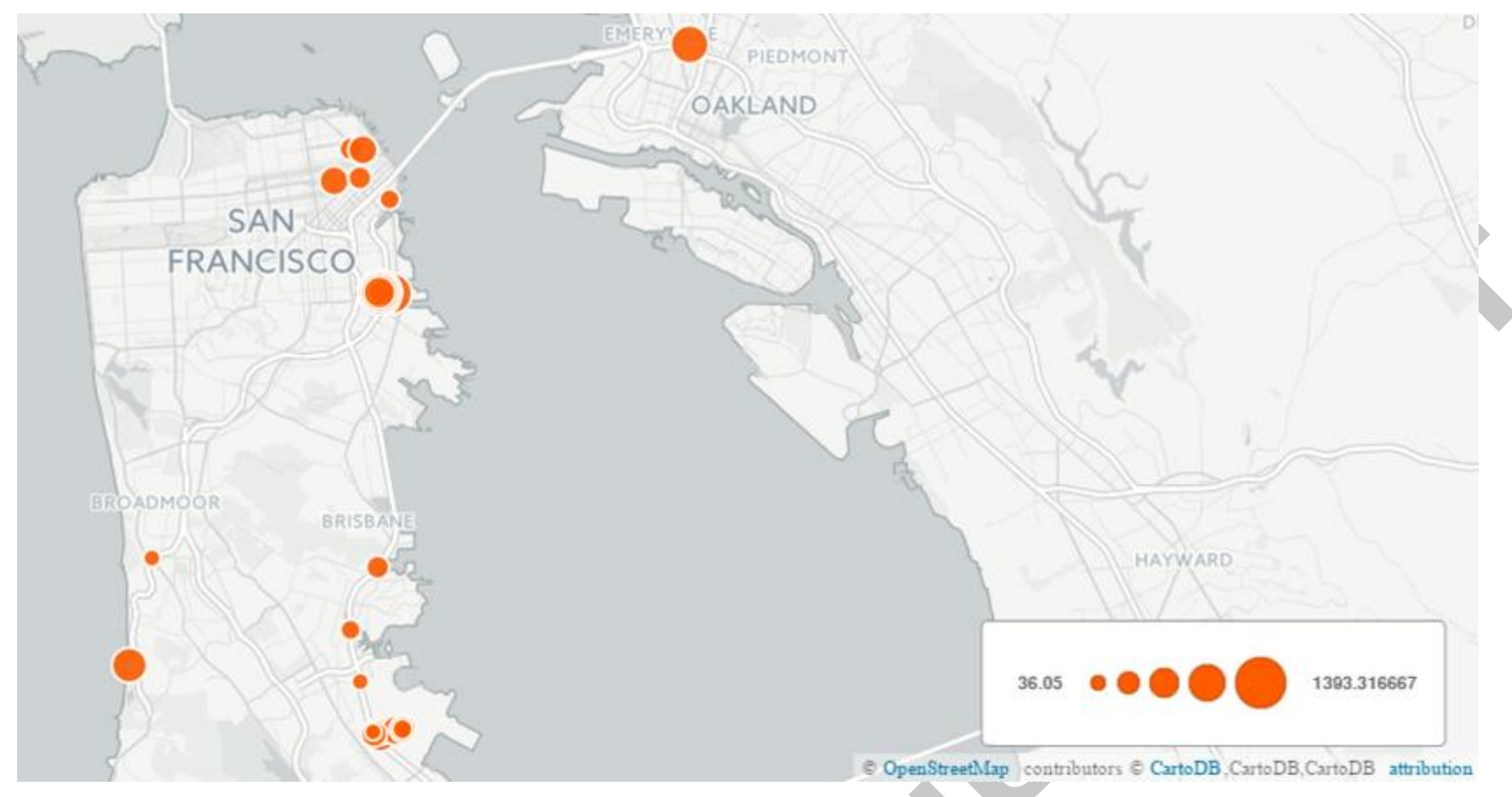

Fig 7. Stop location and stop duration of a single taxi cab (available at: https://jefar.carto.com/builder/805bec26-2582-11e5-b83f$\underline{0 \mathrm{e} 018 \mathrm{~d} 66 \mathrm{dc} 29}$ )

The minimum stop duration is 36.05 minutes and the maximum stop duration is one day (1440 minutes). This information is also provided in the histogram shown in Figure 8 (left). It is observed in the normalized cumulative histogram from Figure 8 (right) that more than $70 \%$ of stop duration are lower than 5 hours (50\% of the stop duration are lower than 2 hours) indicating that most of the drivers take short breaks.
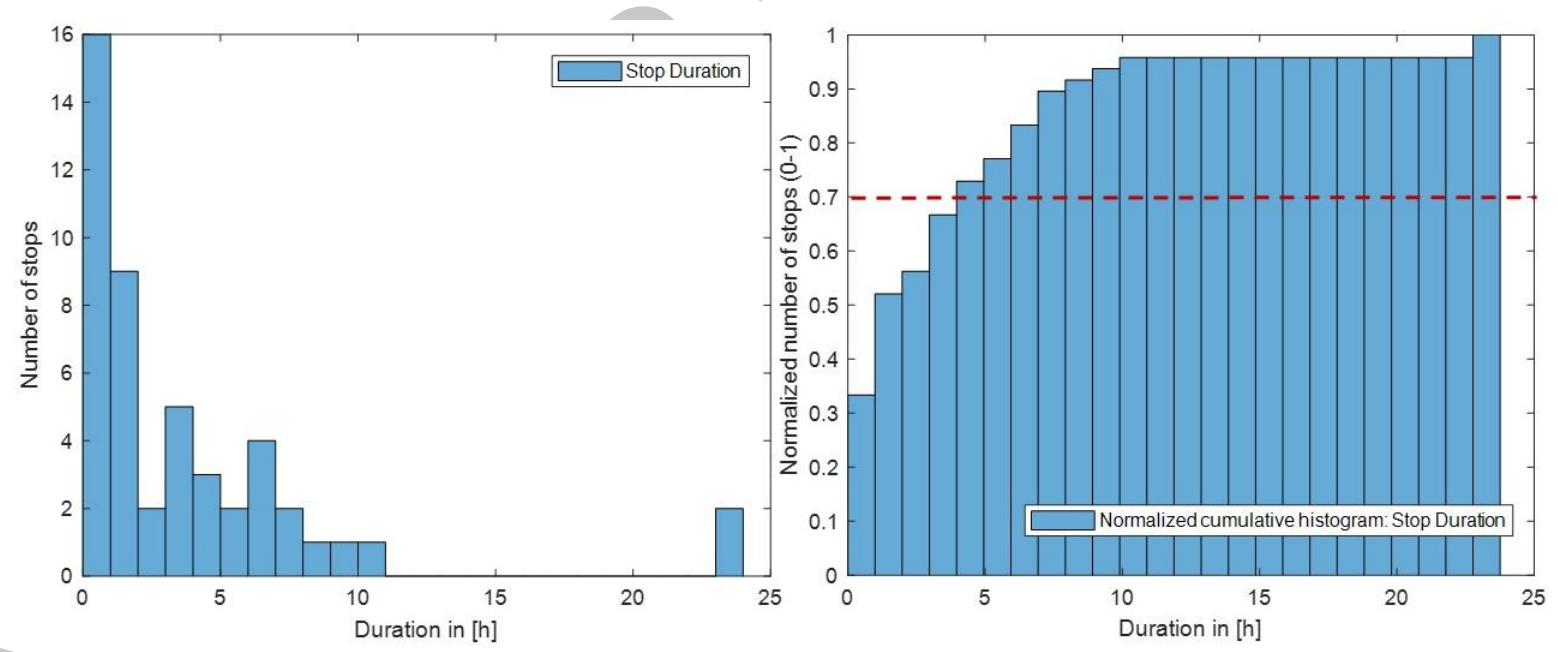

Fig 8. Histogram of the stop time duration of a single taxi cab

Figure 9 shows the histogram of the initial stop time of the taxi vehicle under study. The initial stop time varies between 00:00 to 23:59, therefore, 24 bins of 1 hour duration has been used. Most of their daily stops are done at 3:00 in the night and at noon (with 4 stops) and at 15:00 and at 19:00 (with 5 stops) in the afternoon-evening period. This information is similar to the one presented in [12], obtained through the Taxi Passenger Enhancement Program (TPEP) in NYC. 


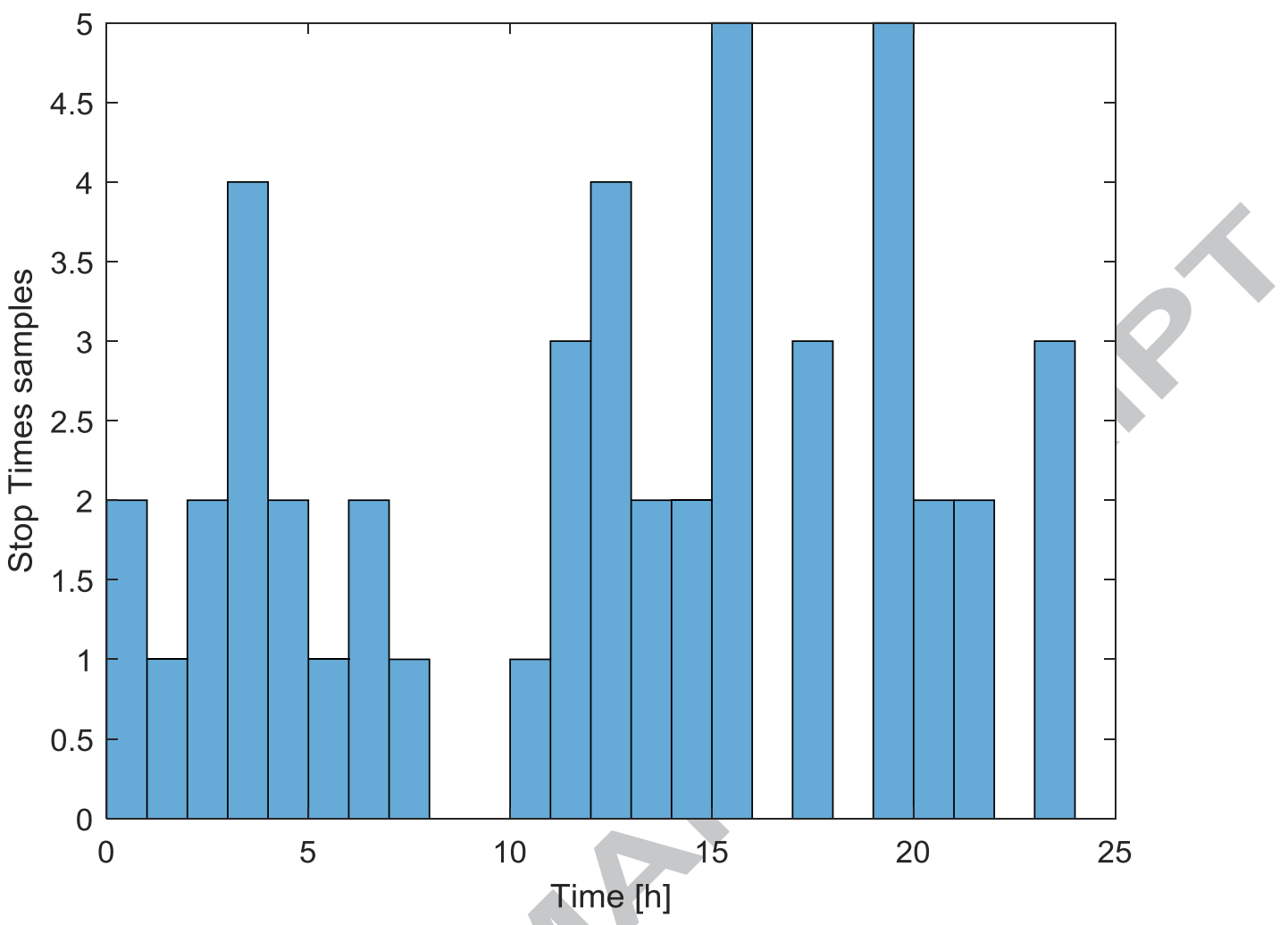

Fig 9. Histogram of the initial stop time of a single taxi cab

The average speed are clearly different depending on the taxi occupancy. When the taxi is empty, the driver is slowly moving around some crowded places or waiting at fixed locations When the taxi picks up a new customer, it is driven directly to the final destination. Figure 10 shows the speed histograms profiles for both cases. It is observed that there are a great number of speed samples (around 6000) below $3 \mathrm{~km} / \mathrm{h}$ (corresponding to the first step of the dotted green histogram) when the taxi is empty, while the highest number of speed samples when the taxi is occupied is $15.78 \mathrm{~km} / \mathrm{h}$ (corresponding to the third step of the blue histogram). The average speed when the taxi is empty is $16.14 \mathrm{~km} / \mathrm{h}$ and this value is almost doubled (increasing to $26.7 \mathrm{~km} / \mathrm{h}$ ) when the taxi is carrying a customer. When the taxi is occupied, the speed distribution is broaden, reaching higher values, which indicates that the taxi driver is driving to the final destination as fast as possible. 


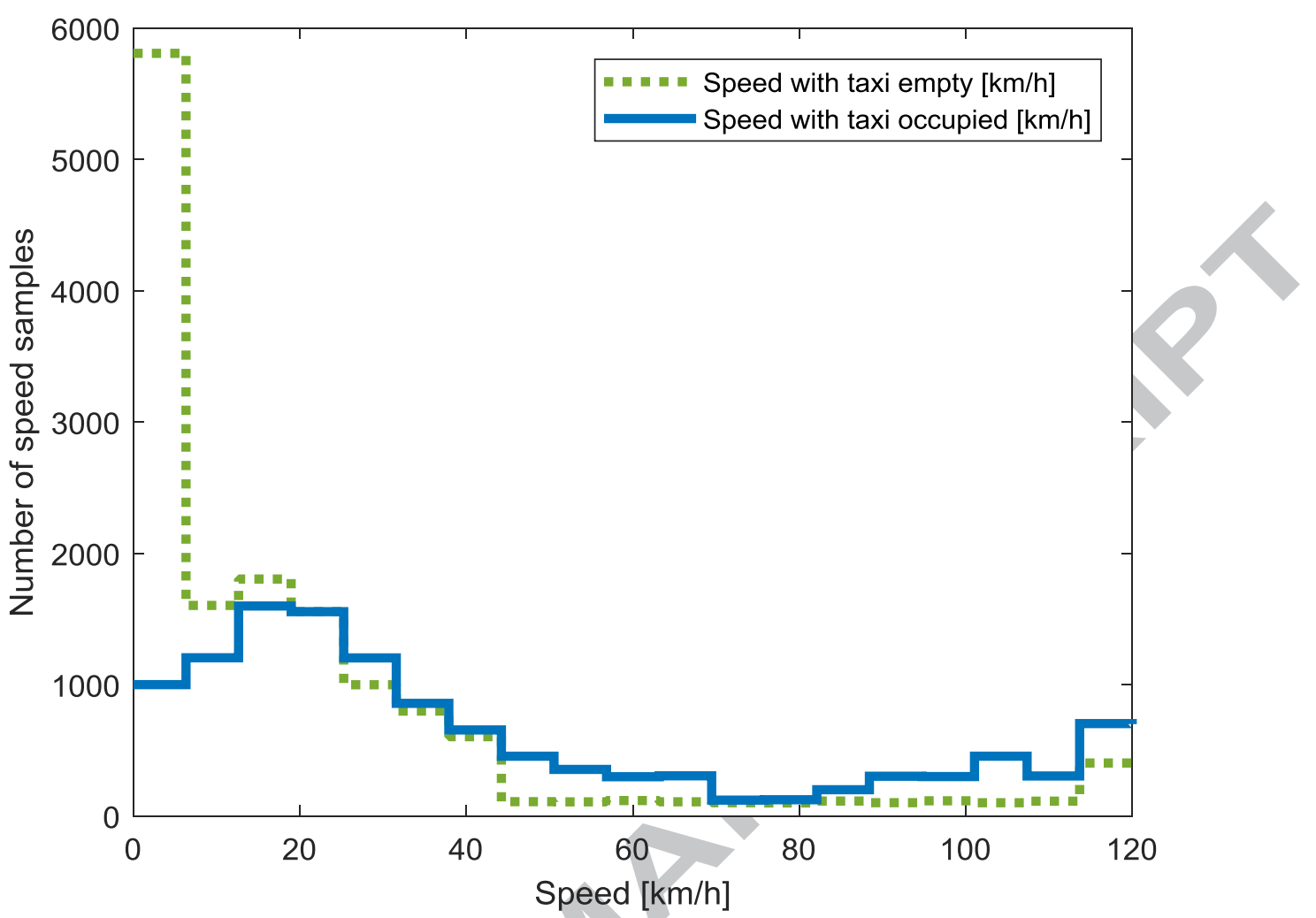

Fig 10. Speed histograms for empty and occupied taxi cases

\subsubsection{Spatio-temporal energy calculation}

The time-dependent electric energy recharged during each stop is given in Figure 11. It is observed that during 12 charging episodes, the energy demanded is bigger than the nominal capacity of the battery. The electrificability rate for this particular vehicle will be $75.2 \%$, indicating than most of trips can be done using an EV without modifying the driver's monthly mobility behavior.

The battery capacity data was based on the specifications of 2015 Nissan Leaf ( $24 \mathrm{kWh})$, but the brand new 2017 Nissan Leaf can also be equipped with a $30 \mathrm{kWh}$ (denoted by a blue dotted line). If this particular model is selected as electric taxi cab, only 10 of the charging episodes would require more than $30 \mathrm{kWh}$, and the electrificability rate would increase up to $79.6 \%$. There are other EVs on the market that are currently been used as taxis with a significant bigger battery capacity such as BYD E6 (with $61.4 \mathrm{kWh}$ ) and Tesla model S (with $100 \mathrm{kWh}$ ). If these vehicles were used as taxicabs, all registered trips could be covered, without modifying the current taxi mobility pattern. 


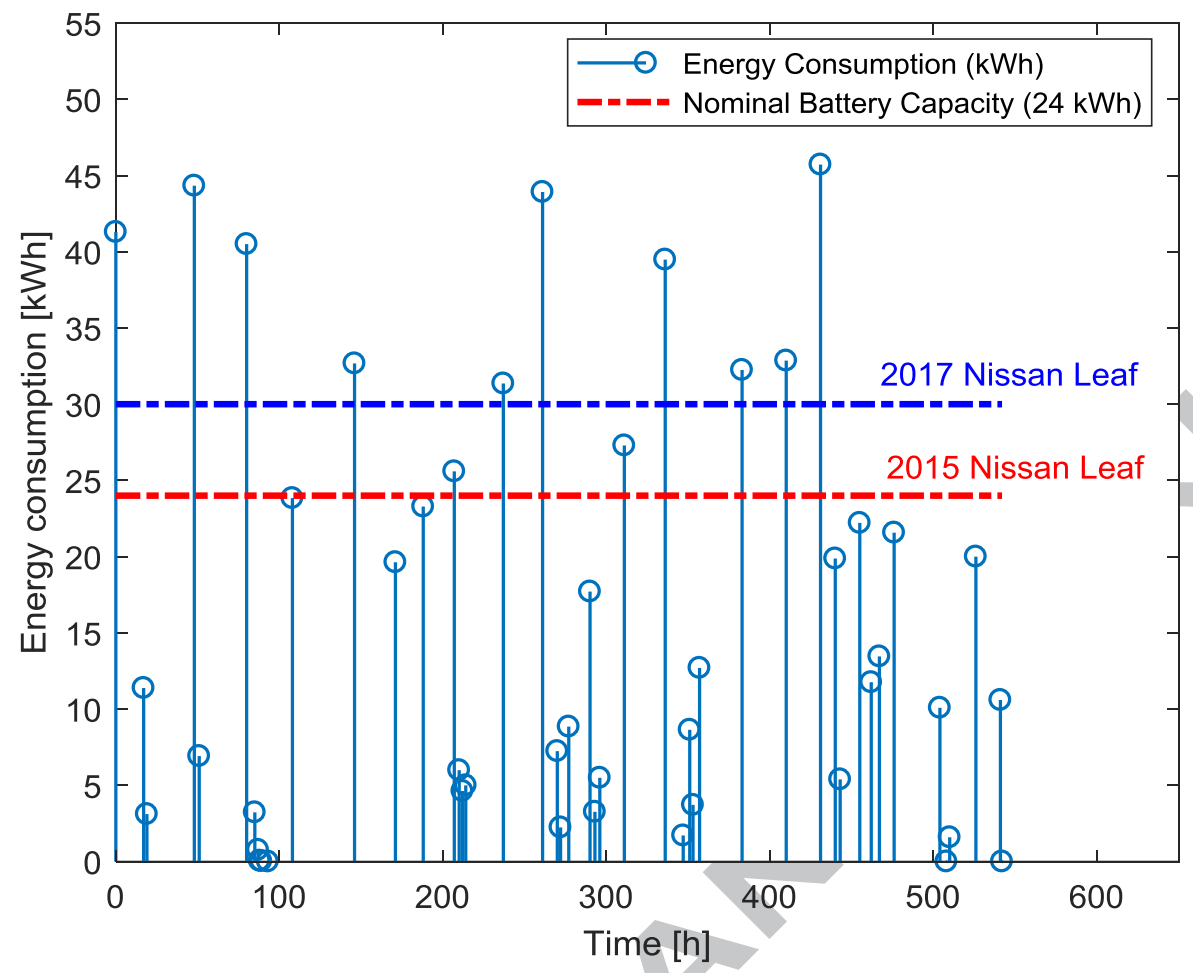

Fig 11. Energy demanded by a single taxi cab during one month of study

In Figure 12, the results of the spatial electric energy demand are presented. There are two main areas showing the highest energy demand. Zooming on the left Figure 12, it is observed that one of the areas is located in the fleet parking (Yellow Cab Access Road) and the other is located in the San Francisco International Airport. 


\section{ACCEPTED MANUSCRIPT}

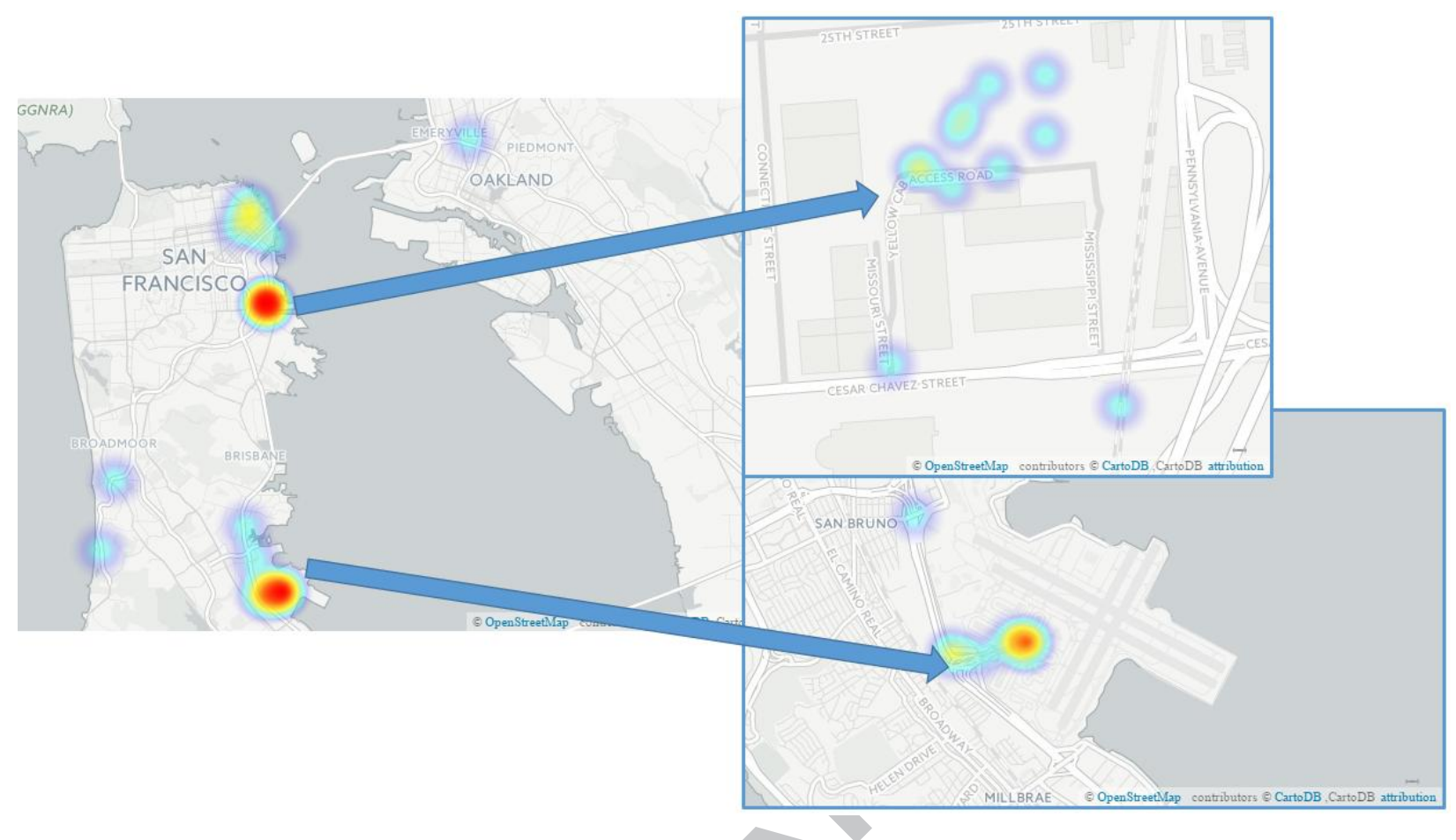

Fig 12. Spatial energy demanded by a single taxi cab (available at: https://jefar.carto.com/builder/1a5191ee-2585-11e5-b0610e0c41326911/embed ) 


\subsection{Taxi fleet analysis}

In this section, the analysis performed for a single taxi cab is extended over the rest of the vehicles in the taxi fleet. Also, a brief economics analysis interesting for fleet managers that are currently transitioning to EV taxis is presented.

\subsubsection{Mobility information}

In this section, all taxi fleet trajectories over one month are studied. The number of vehicles analyzed are 460 with 23 days as the average number of registered days per vehicle. The average number of stops (above 30 minutes) per vehicle is 60, giving an average number of trips of 61 per vehicle, corresponding to an average value of 2.65 trips per day per vehicle as it is shown in Figure 13.

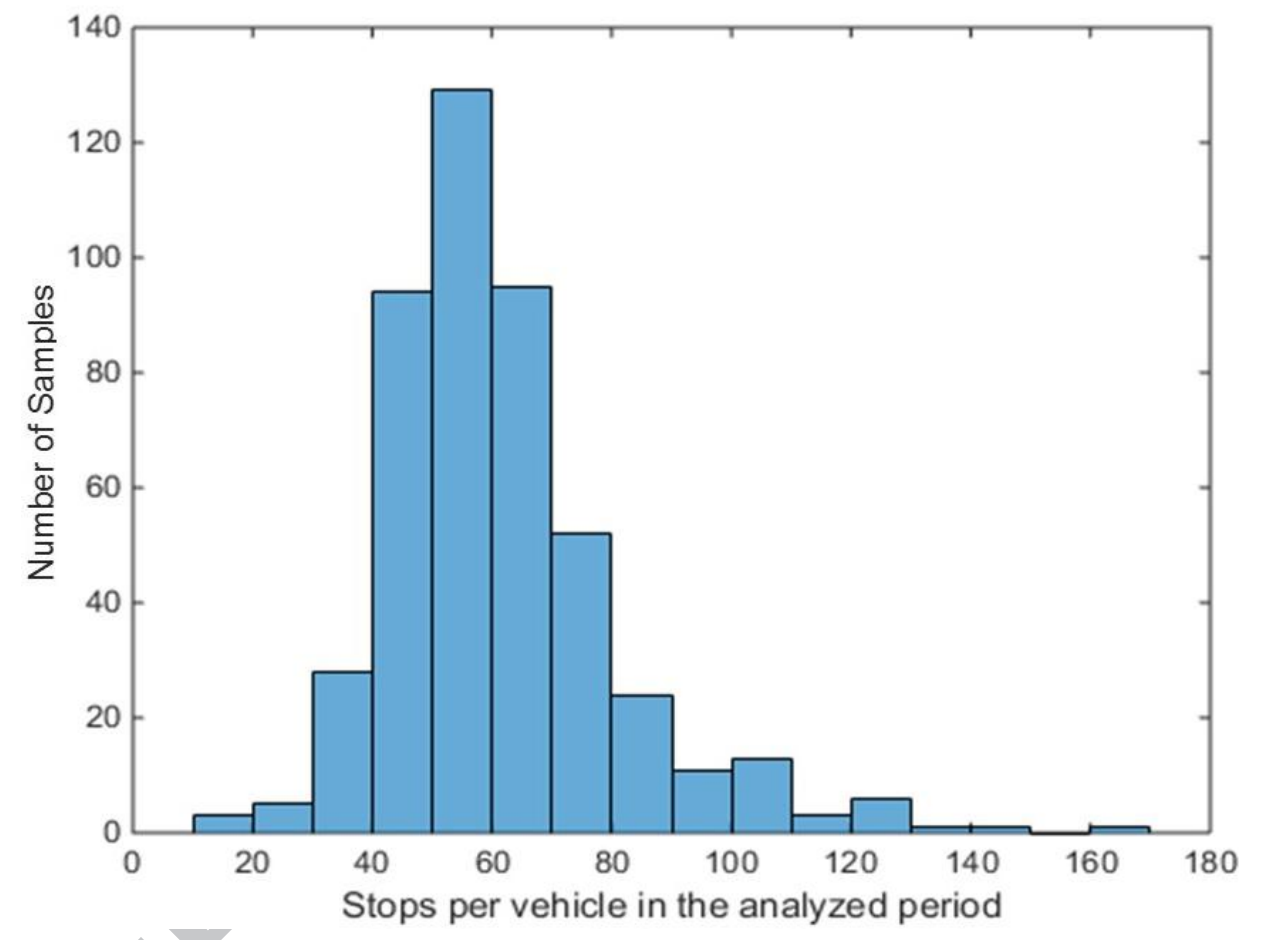

Fig 13. Histogram of number of stops per vehicle.

Analyzing the stops duration, the maximum stop duration is 413.5 hours (17 days) and $99.36 \%$ of the stop duration are lower than 24 hours. Focusing in stop durations lower than 24 hours, the average stop duration is 2 hours 34 minutes as it is shown in Figure 14. 


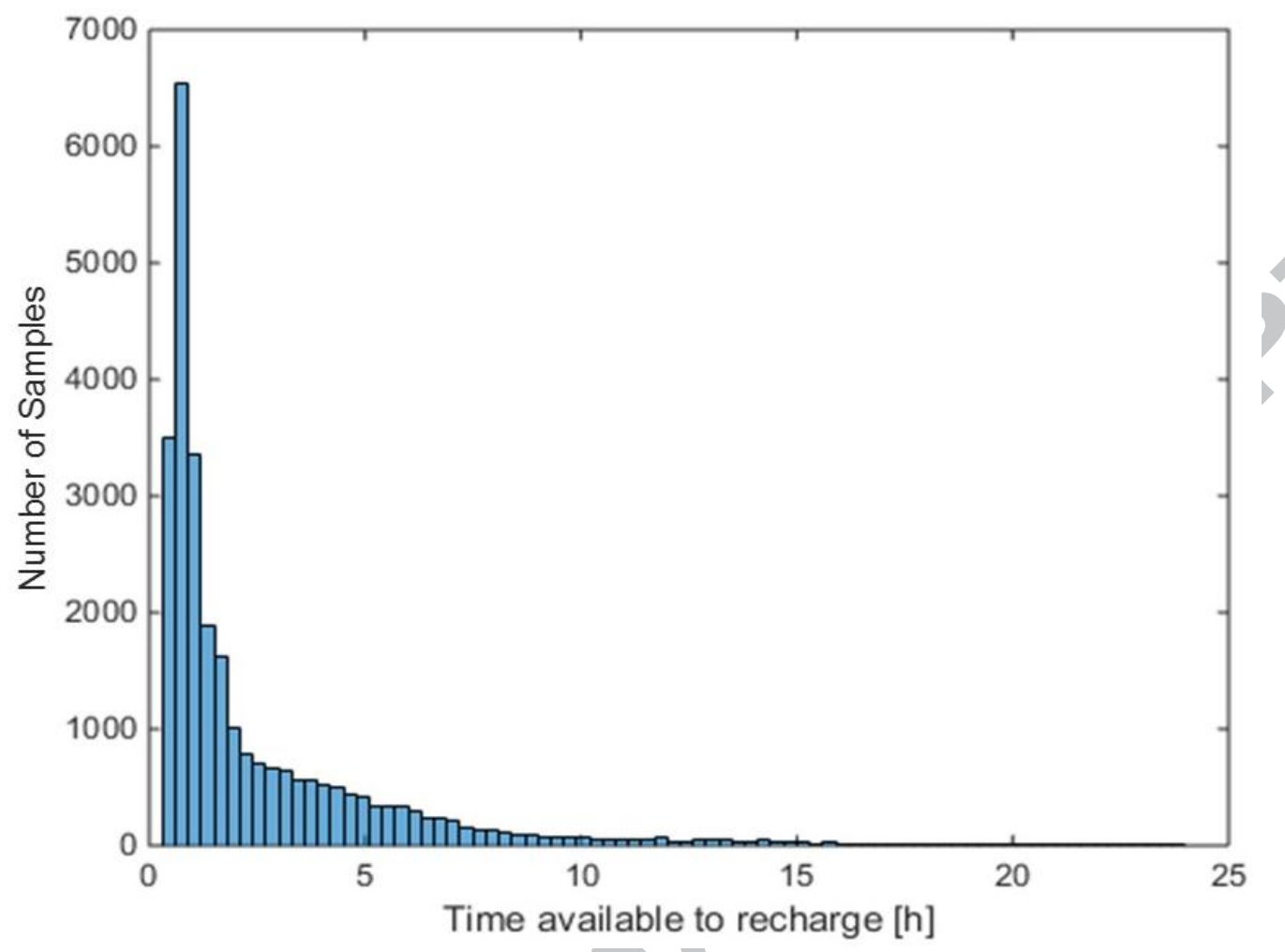

Fig 14. Histogram of the stop duration (above 30 minutes and below 24 hours) for the taxi fleet.

\subsubsection{Spatio-temporal energy calculation}

The histogram of the total electricity demanded by the taxi fleet during its stops is shown in Figure 15. According to this figure, the energy charged during most of the stops is less than $5 \mathrm{kWh}$ (1900 charging events) with a second peak around $8 \mathrm{kWh}$ (1000 charging events). Adding up all the energy recharged during all these charging events, generates a total energy demand of $138.5 \mathrm{MWh}$ in one month. The electrificability rate of this particular taxi fleet is $74.3 \%$, using a 2015 Nissan Leaf. 


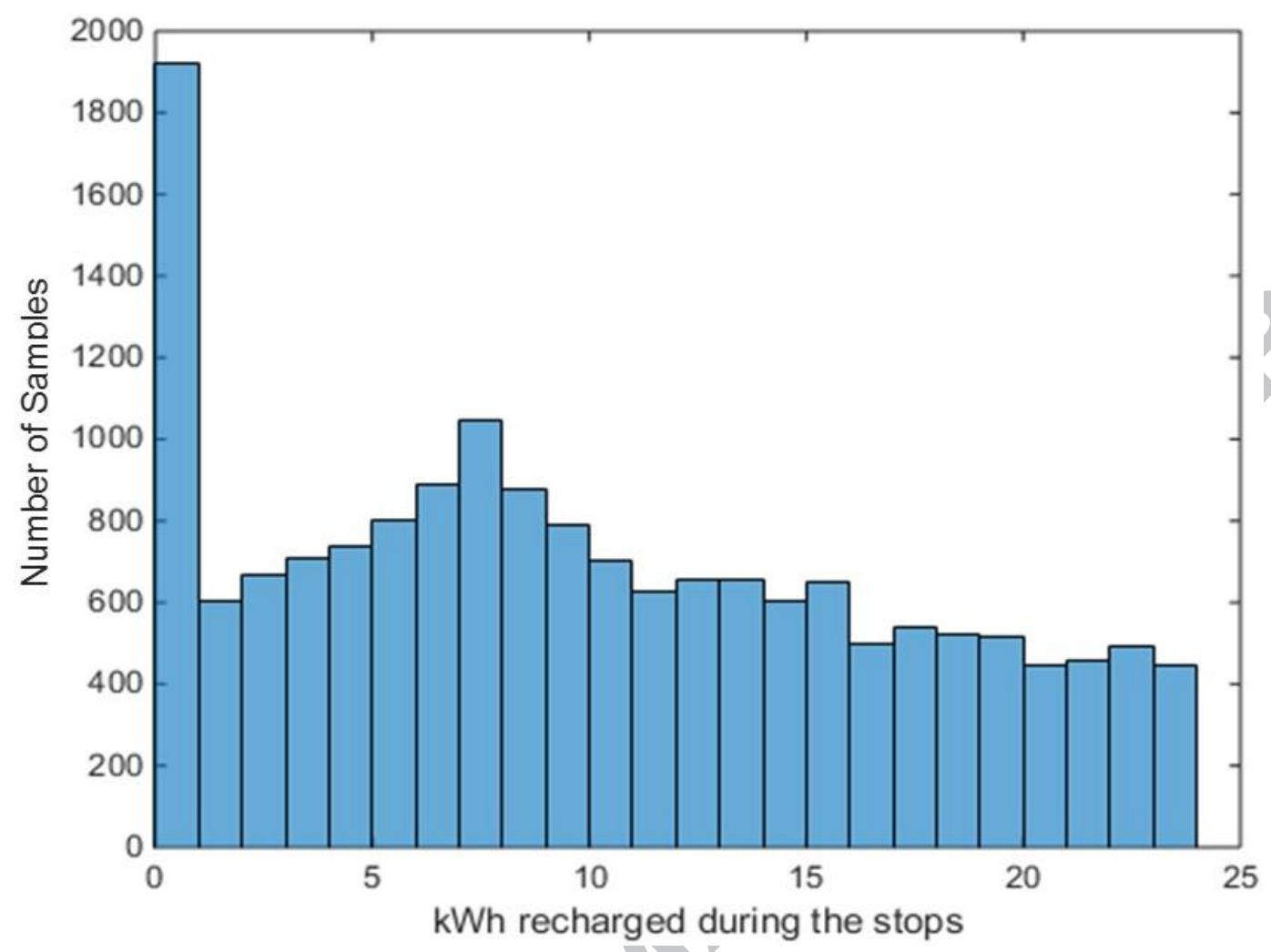

Fig 15. Histogram of the total energy demanded during the taxi fleet stops

The spatial electric energy demand for the complete EV taxi fleet is shown in Figure 16, with a colormap varying between $3.53 \mathrm{kWh}$ (denoted by yellow dots) to the maximum battery capacity, $24 \mathrm{kWh}$ (denoted by dark red dots). This information will help the fleet manager to determine when and where the taxi fleet will recharge and the prediction of the energy demand for each recharge, allowing the evaluation of the total estimated electricity cost. In this case, a proprietary charging station infrastructure for this EV taxi fleet could be installed, similar to the one deployed by Tesla [40]. Based on this information, an optimization analysis should be done to determine exact location of this charging network [41-42]. With the mobility information available, it is also possible to combine the charging infrastructure deployment with the development of energy-efficient paths to minimize the electric consumption [43] and even to propose additional shorter stops to allow partial recharging, as proposed in [44], significantly increasing the electrificability rate of this EV taxi fleet.

The prediction of energy demand by this particular taxi fleet is also compared with the current DC-fast charging infrastructure available in San Francisco (denoted by blue dots in the Figure 16) [45]. It is observed that most of the charging stations in this city are located around the city center and at South San Francisco, but there is a wide area of the city, which is completely uncovered. It is important to highlight that the DCfast infrastructure shown in this figure is public and it can be used by any other driver, while the proposed charging infrastructure could only be used to charge to this specific taxi fleet. The public DC-fast charging stations have been deployed taking into account the current market of EV in California [46] and its forecast.

This total spatio-temporal electricity demand can also be used by the local electric distribution system operator (DSO) to evaluate the impact of the recharging process of this taxi fleet on the electric grid, analyzing if the current network have enough capacity to add new DC-fast chargers, determining the additional investment costs required to reinforce this network to assure a safely charger deployment. 


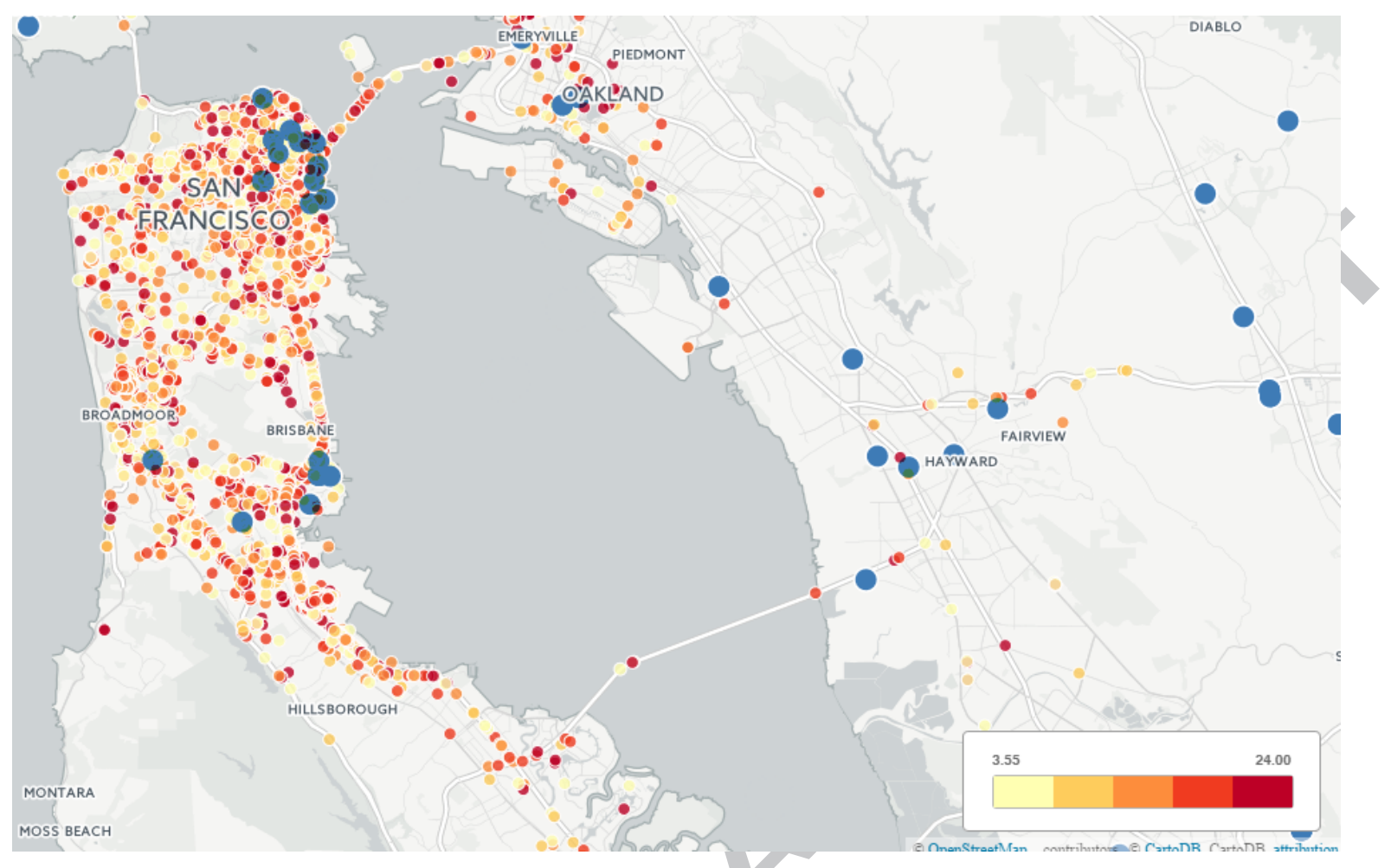

Fig 16. Prediction of the energy demanded by taxi fleet over one month (yellow-red dots) and current location of the DC-fast chargers (blue dots) (available at: https://jefar.carto.com/builder/7ace25e0-3fe8-11e6-a816-0ecfd53eb7d 3/embed).

\subsubsection{Economics of electric taxi fleet ownership and sensibility analysis}

The total cost of ownership (TCO) for an electric taxi is one of the key factors for the fleet decision maker. This TCO includes:

- Purchasing cost. The initial purchase cost of an EV is higher than the ICE equivalent vehicle, mainly due to the cost of the batteries and the low production volumes. In this study, it is assumed that the purchase cost of an ICE conventional taxi is $\$ 20,000$ and the purchase cost of a 2015 Nissan Leaf is $\$ 29,000$, allowing an increase of $10 \%$ of the purchase cost [12].

- Service, maintenance and repairs (SMR). According to different studies [12], [47], maintenance and repair costs are lower in electric vehicles than in conventional ICE cars, because EVs have fewer moving parts. According to [47], it is assumed a maintenance cost of $\$ 4.6 / 100 \mathrm{~km}$ for ICE vehicle and $\$ 2.5 / 100 \mathrm{~km}$ for EV vehicle. From the previous mobility study, the average travelled distance in one month for a taxi cab belonging to this particular fleet has been evaluated and it is around $2133 \mathrm{~km}$, therefore the SMR cost is $\$ 98.13$ for the conventional ICE taxi and $\$ 53.33$ for an EV taxi, leading to a reduction of $84 \%$ of the SMR costs.

- Battery replacement. Battery packs from EVs can degrade over time, reaching the end of their life when their nominal capacity has reduced to $80 \%$. According to [12], a battery pack will degrade to $80 \%$ capacity after 2850 quick charges. From the previous mobility study, the average number of quick charge per day is 2.6. This means that it will be necessary to replace the EV taxi battery pack in 3 years. Most of current EV manufacturers offer more than 3 years of battery warranty (even Nissan is currently offering a 5 year battery warranty), therefore the battery replacement cost will be not considered in this study. There is also another possibility: battery packs can also be leased, shifting the uncertainty of the residual value and maintenance costs to the leasing provider. In this case, the fleet manager must pay a variable monthly fee for the battery leasing, but this scheme allows a competitive initial purchase cost. 
- Fuel costs. Assuming that the average travelled distance in one month is $2133 \mathrm{~km}$, the total electric energy demanded is $297.21 \mathrm{kWh}$ if an EV is used as taxi cab. If a conventional ICE vehicle were used, the total fuel consumption is given by $2133 \mathrm{~km} \cdot 14.51 / 100 \mathrm{~km}=313.58 \mathrm{l}=82.84$ gallons. Comparing the current average price for electricity and gasoline in San Francisco [48] it is observed that the total cost will be $297.21 \mathrm{kWh} \cdot 0.23 \$ / \mathrm{kWh}=\$ 69.25$ if an EV taxi is used or 82.84 gallon $\$ 3.692 /$ gallon $=\$ 305.86$ if a conventional ICE taxi is used, allowing a reduction of $77.36 \%$ of the fuel costs.

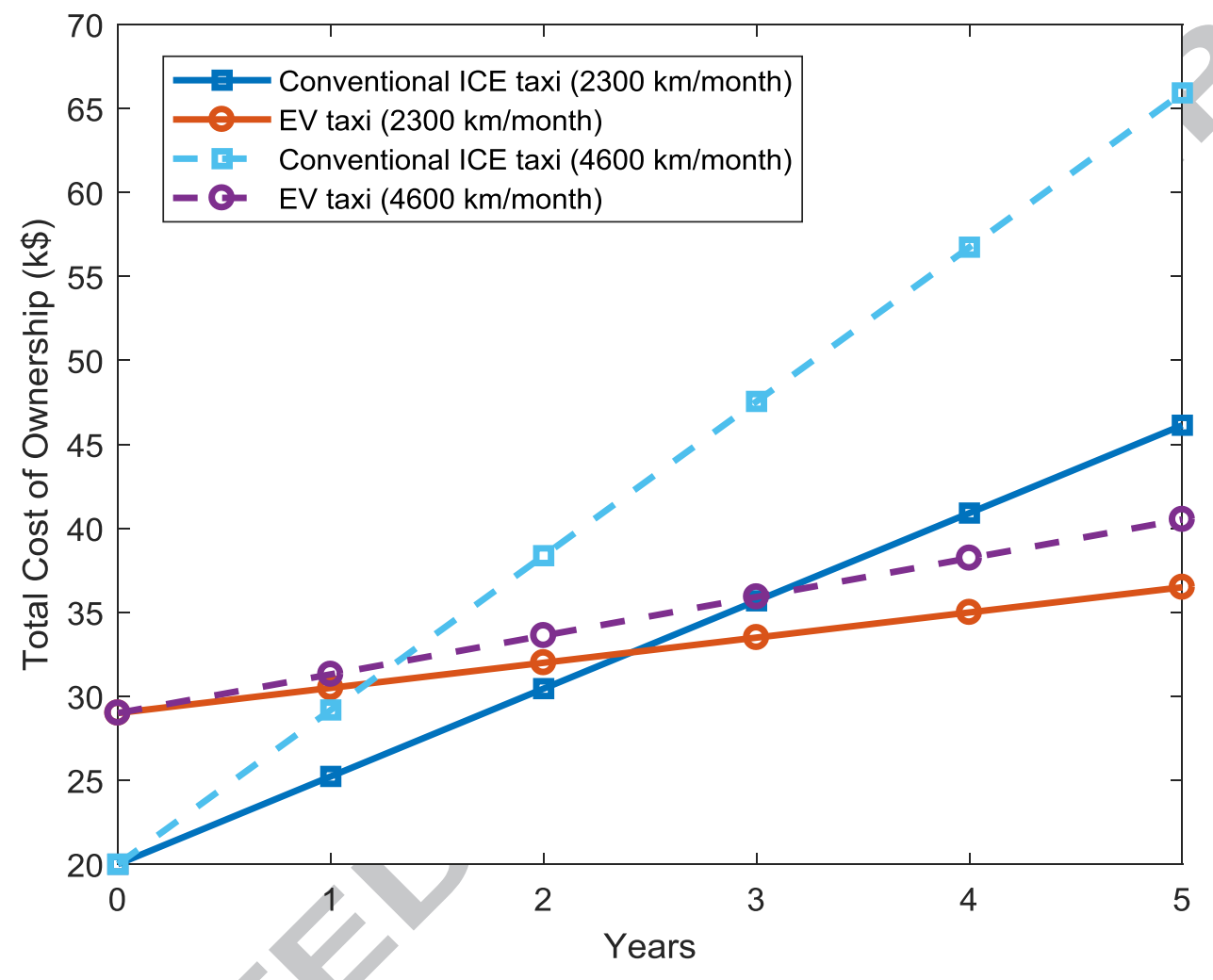

Fig 17. Total cost of ownership comparison (conventional ICE taxi vs proposed EV taxi).

Based on the previously described costs, Figure 17 shows the Total Cost of Ownership (TCO) for the two types of vehicles. According to [12], the current taxi regulations require that taxi vehicles must be retired from the taxi service after between 3 and 7 years. In this cost analysis, it is assumed an average 5-year vehicle life.

Assuming an average mileage of $2300 \mathrm{~km} / \mathrm{month}$, the crossover point between the ICE vehicles and EVs will occur before 3 years. The final cost reduction (at the end of the fifth year) will be $20.91 \%$. This value is very conservative because, when the average mileage for this particular taxi fleet has been evaluated, it was considered all vehicles, including some taxis that were parked during most of the time). Doubling the monthly average mileage to be more realistic, the final cost difference between ICE vehicle and EVs will reach $38.53 \%$ (see dotted lines in Figure 17).

It is important to study some other factors, which directly affect the feasibility of the proposed system.

\section{- Factors affecting to the vehicle}

- Vehicle price. Battery prices are the main factor that affects to the final purchasing EV cost, but according to [47] the price of the battery pack is declined by $14 \%$ annually, from $\$ 1000 / \mathrm{kWh}$ in 2007 to $\$ 227 / \mathrm{kWh}$ in 2016 , and the forecast is to reach $\$ 150$ $\$ 170 / \mathrm{kWh}$ in 2025 and less than $\$ 100 / \mathrm{kWh}$ in 2030 [49].

- Electricity and gas price. Although the current electricity price in San Francisco household is $55.5 \%$ higher than the US nationwide average $(\$ 0.21 / \mathrm{kWh}$ vs. $\$ 0.135 / \mathrm{kWh}$ ), the electricity price has remained almost constant in the last 5 years [48]. 
This value is significantly lower than Japan $(\$ 0.26 / \mathrm{kWh})$ or Europe $(\$ 0.30 / \mathrm{kWh})[50]$. Current gas price in San Francisco is around \$3/gallon (\$0.7925/liter), which is $23.1 \%$ more than the national average value, but it is still lower than the average price in Europe or Japan (\$1.18/liter) [51].

- Battery capacity. Battery capacity has increased $275 \%$ in the last 5 years. The nominal value for a conventional EV was around 16-20 kWh in 2011 and this value has increased to $60-80 \mathrm{kWh}$ in 2017 [52]. Increasing the battery capacity will increase the total range of the vehicle.

- Affecting to the charging infrastructure.

$\circ$ Charging power. Due to the increment on the nominal battery capacity for the new EV models, the demand for more powerful charging stations has also increased. The nominal power of the current Tesla Supercharger is $120 \mathrm{~kW}$, but some manufactures have recently presented $150-350 \mathrm{~kW}$ ultrafast DC chargers [53], dividing by two the time required to charge the vehicle. With this new charger technology, EVs can be charged in less time, requiring small breaks.

- Wireless charging. With this technology, it is possible to recharge the batteries as the EVs are moving over a special roads, which include wireless inductive chargers. In this case, it would eliminate the need to perform stops to recharge [54].

\section{- Affecting to the mobility.}

$\circ$ Average trip length. The geography of the city will affect the feasilibity of the EV taxi fleet. Large cities with where point of interest (POI) are widespread are less suitable than other cities with closer POIs.

In order to generalize the case study to other taxi fleets in other cities around the world, authors have developed an Android app, which uses the smartphone's built-on sensor to register the route (registering GPS traces), the travelled distance and the speed. With this information, and the generic procedure developed in this work, it is possible to extend this analysis to other fleet managers and perform feasibility studies of EV deployment in their own fleets, providing an electrificability rate value and the fuel savings on each trip, as it is shown in Figure 18.

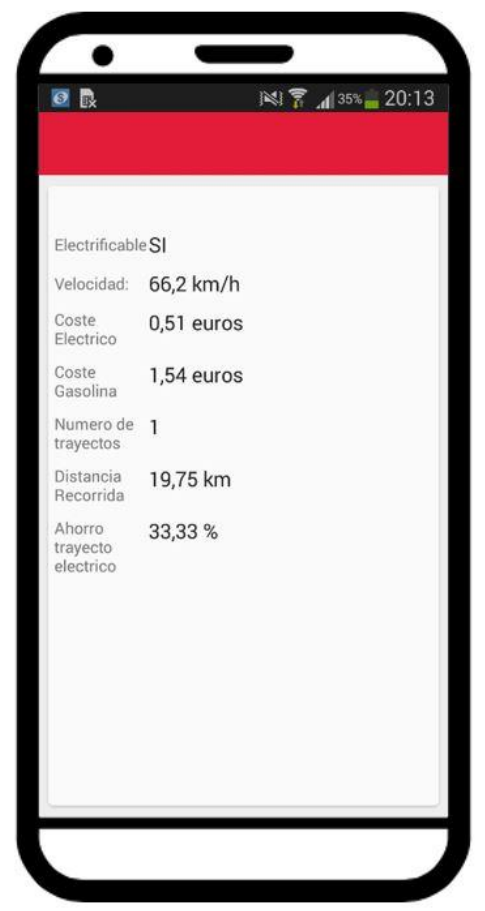

Fig 18. Android App to track customer daily routes. 


\section{Conclusions and discussions}

In this work a feasibility study for the introduction of EVs in a real taxi fleet has been presented. For this purpose, GPS measurements of 460 taxis that work in San Francisco have been collected and analyzed. From measured data a mobility pattern that considers information of trip coordinates (latitude, longitude and terrain elevation), trip duration, stops and taxi occupancy has been determined. In this way, the GPS raw data is used to calculate the total distance and the average vehicle speed per trip. In order to estimate how many trips could potentially be done by EVs an electric consumption model based in the battery capacity of Nissan Leaf (2015 model) taxis has been performed. Validation results of the electric consumption model performed under the LA4 test cycle, show that taxi trips that cover a distance less than $160 \mathrm{~km}$ could be done by an EV.

The feasibility analysis shows in the case of a typical Nissan Leaf taxi, that the electrificability rate is 75.2\% (raising up to 80\% for the new 2017 model) taking into account to the distance travelled, duration of trips and energy demanded. If more recent EVs, such as BYD E6 or Tesla model S are used, the electrificability rate can increase up to $100 \%$. For the taxi fleet, this value is $74.3 \%$ of the total trips. According with these results, more than $65 \%$ of the fleet trips are compatible with the operation of a typical EV used as taxi. Economic calculations show that introducing EVs in the taxi fleet increase in $10 \%$ the purchase cost of the taxis, however SMR and fuel costs can be reduced $77 \%$ and $84 \%$ respectively, resulting in a reduction of $20.91 \%$ in total costs.

By means of the mobility analysis the spatio-temporal electric energy demanded has been estimated and compared with the current public DC-fast charging infrastructure available in San Francisco. This comparison reveals that the current EV charging infrastructure do not cover all areas with expected energy demand increment and a private charging infrastructure should be installed to cover the new demand generated by the electrified taxi fleet.

The feasibility study presented in this paper shows that real GPS measurements can be used as input of a data-driven analysis to evaluate the introduction of EV in urban transportation. The results of this analysis are useful for taxi fleet owners because the estimation is based on realistic conditions. Also, this analysis can be used for DSOs to design and reinforce the electrical grid in order to locate EV charging points where energy is really needed. Based on this work, authors have developed a generic tool which allows extend the feasibility analysis to any public fleet in a crowded city.

\section{References}

[1] Demographia, "Demographia World Urban Areas. 13th Edition. 2017" [Online]. Available: http://www.demographia.com/db-worldua.pdf [Last access: 11/04/2017]

[2] The World Bank. IBRD-IDA. "Urban Development". [Online]. Available: http://data.worldbank.org/topic/urbandevelopment [Last Access 04/04/2017]

[3] World Health Organization-WHO. "WHO Global Urban Ambient Air Pollution Database (update 2016)". [Online]. Available: http://www.who.int/phe/health_topics/outdoorair/databases/cities/en/ [Last access: 11/05/2017]

[4] R. Godina, E.M.G. Rodrigues, N.G. Paterakis, O. Erdinc, J.P.S. Catalão, "Innovative impact assessment of electric vehicles charging loads on distribution transformers using real data", Energy Conversion and Management, Volume 120, 15 July 2016, Pages 206-216, ISSN 0196-8904, https://doi.org/10.1016/j.enconman.2016.04.087

[5] Department for Environment Food \& Rural Affairs. "Effects of air pollution”. [Online]. Available: http://ukair.defra.gov.uk/air-pollution/effects

[6] Ya Wu, Li Zhang, "Can the development of electric vehicles reduce the emission of air pollutants and greenhouse gases in developing countries?", Transportation Research Part D: Transport and Environment, Volume 51, March 2017, Pages 129-145, ISSN 1361-9209, https://doi.org/10.1016/j.trd.2016.12.007 
[7] Alfred Wong, "Some less-discussed externalities of contemporary electric vehicle mania in Canada", Energy, Volume 120, 2017, Pages 1025-1033, ISSN 0360-5442, https://doi.org/10.1016/j.energy.2016.11.126.

[8] UK Plug-in Car Grant, [Online]. Available: https://www.gov.uk/government/publications/plug-in-car-grant\#history [Last Access, 21/3/2017]

[9] Sunliang Cao, Konstantin Klein, Sebastian Herkel, Kai Sirén, “Approaches to enhance the energy performance of a zero-energy building integrated with a commercial-scale hydrogen fueled zero-energy vehicle under Finnish and German conditions”, Energy Conversion and Management, Volume 142, 15 June 2017, Pages 153-175, ISSN 01968904, https://doi.org/10.1016/j.enconman.2017.03.037

[10] “US Promoting Electric Vehicles Act of 2011”, [Online]. Available: https://www.govtrack.us/congress/bills/112/s948 [Last Access, 12/3/2017]

[11] Wenwei Ke, Shaojun Zhang, Xiaoyi He, Ye Wu, Jiming Hao, "Well-to-wheels energy consumption and emissions of electric vehicles: Mid-term implications from real-world features and air pollution control progress", Applied Energy, Volume 188, 15 February 2017, Pages 367-377, ISSN 0306-2619, https://doi.org/10.1016/j.apenergy.2016.12.011

[12] NYC Taxi \& Limousine Commission, "Take Charge. A Roadmap to Electric New York City Taxis", [Online]. Available: http://www.nyc.gov/html/tlc/downloads/pdf/electric taxi_task_force_report_20131231.pdf [Last Access, 25/3/2017]

[13] Canbing Li, Yijia Cao, Mi Zhang, Jianhui Wang, Jianguo Liu, Haiqing Shi \& Yinghui Geng, "Hidden Benefits of Electric Vehicles for Addressing Climate Change, Scientific Reports, 5, 9213, (2015) doi: 10.1038/srep09213 [Online]. Available: http://www.nature.com/articles/srep09213 [Last Access, 21/3/2017]

[14] Transport for London, The Climate Group, Cenex, Energy Saving Trust and TNT. "Plugged-In Fleets. A guide to deploying electric vehicles in fleets". [Online]. Available: http://www.theclimategroup.org/_assets/files/EV_report_final_hi-res.pdf [Last Access, 17/3/2017]

[15] Peter R. Stopher, Stephen P. Greaves, "Household travel surveys: Where are we going?", Transportation Research Part A: Policy and Practice, Volume 41, Issue 5, June 2007, Pages 367-381, ISSN 0965-8564, http://dx.doi.org/10.1016/j.tra.2006.09.005

[15] Natalia V. Andrienko, Gennady L. Andrienko, Salvatore Rinzivillo, "Exploiting Spatial Abstraction in Predictive Analytics of Vehicle Traffic, International Journal of Geo-Information, Volume 4, Issue 2, pp. 591-606, April 2015, https://doi:10.3390/ijgi4020591

[17] Michele De Gennaro, Elena Paffumi, Harald Scholz, Giorgio Martini, GIS-driven analysis of e-mobility in urban areas: An evaluation of the impact on the electric energy grid”, Applied Energy, Volume 124, 1 July 2014, Pages 94116, ISSN 0306-2619, http://dx.doi.org/10.1016/j.apenergy.2014.03.003

[18] Jing Yuan, Yu Zhen, Liuhang Zhang, Xing Xie, Guangzhong Sun. "Where to find my next passenger?" Proceedings of the $13^{\text {th }}$ International Conference on Ubiquitous Computing, pp. 109-118, ACM, 2011. ISBN: 978-1-4503-0630-0 $\underline{\text { https://doi:10.1145/2030112.2030128 }}$

[19] Junghoon Lee; Inhye Shin; Gyung-Leen Park, "Analysis of the Passenger Pick-Up Pattern for Taxi Location Recommendation", in Fourth International Conference on Networked Computing and Advanced Information Management, 2008. NCM '08, vol.1, no., pp.199-204, 2-4 Sept. 2008. https://doi:10.1109/NCM.2008.24

[20] Junghoon Lee, "Analysis on the Waiting Time of Empty Taxis for the Taxi Telematics System", in Third International Conference on Convergence and Hybrid Information Technology, 2008. ICCIT '08. vol.1, no., pp.66-69, 11-13 Nov. 2008. https://doi:10.1109/ICCIT.2008.121

[21] Xintao Liu and Yifang Ban. Uncovering Spatio-Temporal Cluster Patterns Using Massive Floating Car Data. International Journal of Geo-Information, Volume 2, Issue 2, pp. 371-384, May 2013. https://doi:10.3390/ijgi2020371

[22] Zhiyong Tian; Yi Wang; Chen Tian; Fan Zhang; Lai Tu; Chengzhong Xu, "Understanding operational and charging patterns of Electric Vehicle taxis using GPS records", in 2014 IEEE 17th International Conference on Intelligent Transportation Systems (ITSC), vol., no., pp.2472-2479, 8-11 Oct. 2014. https://doi:10.1109/ITSC.2014.6958086

[23] Nivan Ferreira, Jorge Poco, Huy T. Vo, Juliana Freire, and Cláudio T. Silva. 2013. "Visual Exploration of Big Spatio-Temporal Urban Data: A Study of New York City Taxi Trips". IEEE Transactions on Visualization and Computer Graphics 19, 12 (December 2013), 2149-2158. http://dx.doi.org/10.1109/TVCG.2013.226 
[24] M. Piorkowski, N. Sarafijanovic-Djukic, and M. Grossglauser. EPFL/Mobility dataset. Crawdad. A Community Resource for Archiving Wireless Data At Dartmouth [Online]. Available: http://crawdad.org/epfl/mobility/20090224/ [Last Access, 17/3/2017]

[25] USGS. Elevation. [Online]. Available: https://nationalmap.gov/elevation.html [Last Access, 13/4/2017]

[26] Green, R. M. Spherical Astronomy. New York: Cambridge University Press, 1985

[27] Fraile-Ardanuy, J., Alvaro-Hermana, R., Rinzivillo, S., Deliverable 6.1. DATA science for SIMulating the era of electric vehicles, DATASIM. FP7-ICT-270833. Hasselt (Belgium), 2014.

[28] Larminie, J. and J. Lowry. Electric Vehicle Technology Explained. John Wiley \& Sons, $2^{\text {nd }}$ Edition, 2012

[29] T. D. Gillespie, Fundamentals of Vehicle Dynamics. SAE, 1992.

[30] E. Schaltz, Electrical Vehicle Design and Modeling, Electric Vehicles - Modeling and Simulations. Dr. Seref Soylu (Ed.), InTech, 2011

[31] Mingheng Li, "Li-ion dynamics and state of charge estimation", Renewable Energy, Volume 100, January 2017, Pages 44-52, ISSN 0960-1481, https://doi.org/10.1016/j.renene.2016.06.009

[32] O. Tremblay and L. A. Dessaint, "Experimental Validation of a Battery Dynamic Model for EV Applications", EVS24 International Battery, Hybrid and Fuel Cell Electric Vehicle Symposium, World Electric Vehicle Journal, Vol. 3, pp.110, 2009.

[33] F. Marra, G.Y. Yang, C.T. Traeholt, E Larsen, C.N. Rasmussen, S. You, "Demand Profile Study of Battery Electric Vehicle under Different Charging Options", IEEE Power and Energy Society General Meeting, 2012, vol., no., pp.17, 22-26 July 2012. https://doi:10.12691/ajmo-3-2-2

[34] S. Castano, L. Gauchia, E. Voncila, J. Sanz, "Dynamical modeling procedure of a Li-ion battery pack suitable for real-time applications", Energy Conversion and Management, Volume 92, 1 March 2015, Pages 396-405, ISSN 01968904, https://doi.org/10.1016/j.enconman.2014.12.076

[35] Premananda Pany, R.K. Singh, R.K. Tripathi, "Active load current sharing in fuel cell and battery fed DC motor drive for electric vehicle application", Energy Conversion and Management, Volume 122, 15 August 2016, Pages 195-206, ISSN 0196-8904, https://doi.org/10.1016/j.enconman.2016.05.062

[36] J. G. Hayes, R. P. R. de Oliveira, S. Vaughan and M. G. Egan, "Simplified electric vehicle power train models and range estimation," 2011 IEEE Vehicle Power and Propulsion Conference, Chicago, IL, 2011, pp. 1-5. http://doi.org/10.1109/VPPC.2011.6043163

[37] J. G. Hayes and K. Davis, "Simplified electric vehicle powertrain model for range and energy consumption based on EPA coast-down parameters and test validation by Argonne National Lab data on the Nissan Leaf," 2014 IEEE Transportation Electrification Conference and Expo (ITEC), Dearborn, MI, 2014, pp. 1-6. http://doi.org/10.1109/ITEC.2014.6861831

[38] Nissan, "Nissan, New York City Launch LEAF Electric Vehicle Taxi Pilot", [Online] Available: http://nissannews.com/en-US/nissan/usa/releases/nissan-new-york-city-launch-leaf-electric-vehicle-taxi-pilot [12/01/2017]

[39] Taxi Electric. [Online] Available: http://www.taxielectric.nl/en/ [15/12/2016]

[40] Tesla Supercharger Map [Online] Available: https://www.tesla.com/supercharger [17/10/2017]

[41] Hua Cai, Xiaoping Jia, Anthony S.F. Chiu, Xiaojun Hu, Ming Xu, Siting public electric vehicle charging stations in Beijing using big-data informed travel patterns of the taxi fleet, Transportation Research Part D: Transport and Environment, Volume 33, December 2014, Pages 39-46, ISSN 1361-9209, http://dx.doi.org/10.1016/j.trd.2014.09.003

[42] Wei Tu, Qingquan Li, Zhixiang Fang, Shih-lung Shaw, Baoding Zhou, Xiaomeng Chang, "Optimizing the locations of electric taxi charging stations: A spatial-temporal demand coverage approach", Transportation Research Part C: Emerging Technologies, Available online 23 October 2015, ISSN 0968-090X, http://dx.doi.org/10.1016/j.trc.2015.10.004 
[43] Martin Strehler, Soren Merting, Christian Schwan, "Energy-efficient shortest routes for electric and hybrid vehicles". Transportation Research Part B, Volume 103, September 2017, Pages 111-135. ISSN 0191-2615, https://doi.org/10.1016/j.trb.2017.03.007

[44] Maximilian Schiffer, Grit Walther, "The electric location routing problem with time windows and partial recharging, European Journal of Operational Research", Volume 260, August 2017, Pages 995-1013. ISSN 0377-2217. https://doi.org/10.1016/j.ejor.2017.01.011

[45] Blink Network Charger Location [Online] Available: http://www.blinknetwork.com/blinkMap.html\# [Last Access, $11 / 03 / 2017]$

[46] International Council on Clean Transportation, "California's electric vehicle market. May 2017". [Online] Available: http://www.theicct.org/sites/default/files/publications/CA-cities-EV-update_ICCT_Briefing_30052017_vF.pdf [Last Access, 17/10/2017].

[47] Stefan M. Knupfer, R. Hensley, P. Hertzke, P. Schaufuss, "Electrifying insights: How automakers can drive electrified vehicle sales and profitability", McKinsey\&Company (2017), [Online]. Available: http://www.mckinsey.com/industries/automotive-and-assembly/our-insights/electrifying-insights-how-automakerscan-drive-electrified-vehicle-sales-and-profitability [Last Access, 11/05/2017]

[48] Average Energy Prices, San Francisco-Oakland-San Jose - March 2017 [Online] Available: https://www.bls.gov/regions/west/news-release/averageenergyprices_sanfrancisco.htm [Last Access, 11/05/2017]

[49] Jess Shankleman, "The electric car is revolution is accelerating", 6-7-2017, Bloomberg Businessweek [Online] Available: https://www.bloomberg.com/news/articles/2017-07-06/the-electric-car-revolution-is-accelerating [Last Access, 11/05/2017]

[50] Average Electricity Prices Aroung the World. [Online] Availble: https://www.ovoenergy.com/guides/energyguides/average-electricity-prices-kwh.html [Last Access, 17/10/2017].

[51] Global Petrol Prices. October 2017. [Online] Available: http://www.globalpetrolprices.com/gasoline_prices [Last Access, 17/10/2017]

[52] Chevrolet Bolt. 2017. [Online] Available: http://www.chevrolet.com/bolt-ev-electric-vehicle [Last Access, 17/10/2017]

[53] ABB. ABB Terra High Power Charge System. [Online] Available: http://www.abb.com/cawp/seitp202/c2ed43a8ef2e1de2c12581ae002d26b8.aspx [Last Access, 17/10/2017]

[54] I. Hwang, Y. J. Jang, Y. D. Ko and M. S. Lee, "System Optimization for Dynamic Wireless Charging Electric Vehicles Operating in a Multiple-Route Environment," in IEEE Transactions on Intelligent Transportation Systems, vol. PP, no. 99, pp. 1-18. doi: 10.1109/TITS.2017.2731787 
- Feasibility analysis to introduce electric cars on a taxi fleet is presented

- The mobility requirements are determined by data-driven analysis of real routes

- Based on real routing patterns the spatio-temporal energy demand is calculated

- The electrificability rate reveals that electric cars could cover $75 \%$ of all trips

- Resulting net global costs reduction to introduce electric taxis is $20.91 \%$ 